Old Dominion University

ODU Digital Commons

$4-2020$

\title{
1D Fluid model of RF-Excited Cold Atmospheric Plasmas in Helium with Air Gas Impurities
}

Yifan Liu

Dingxin Liu

Jishen Zhang

Bowen Sun

Aijun Yang

See next page for additional authors

Follow this and additional works at: https://digitalcommons.odu.edu/bioelectrics_pubs

Part of the Fluid Dynamics Commons, and the Plasma and Beam Physics Commons 
Authors

Yifan Liu, Dingxin Liu, Jishen Zhang, Bowen Sun, Aijun Yang, and Michael G. Kong 


\section{D fluid model of RF-excited cold atmospheric plasmas in helium with air gas impurities ${ }^{\circ}$}

Cite as: Phys. Plasmas 27, 043512 (2020); https://doi.org/10.1063/1.5145033

Submitted: 16 January 2020 . Accepted: 21 March 2020 . Published Online: 22 April 2020

Yifan Liu (D), Dingxin Liu (D), Jishen Zhang, Bowen Sun (D), Aijun Yang, and Michael G. Kong

\section{COLLECTIONS}

F This paper was selected as Featured
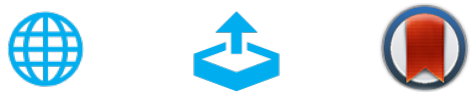

\section{ARTICLES YOU MAY BE INTERESTED IN}

Simulations demonstrate how reactive species are produced by cold atmospheric plasmas

Scilight 2020, 171106 (2020); https://doi.org/10.1063/10.0001190

Machine learning surrogate models for Landau fluid closure

Physics of Plasmas 27, 042502 (2020); https://doi.org/10.1063/1.5129158

Neutralization of ion beam by electron injection: Excitation and propagation of electrostatic solitary waves

Physics of Plasmas 27, 043104 (2020); https://doi.org/10.1063/1.5128523

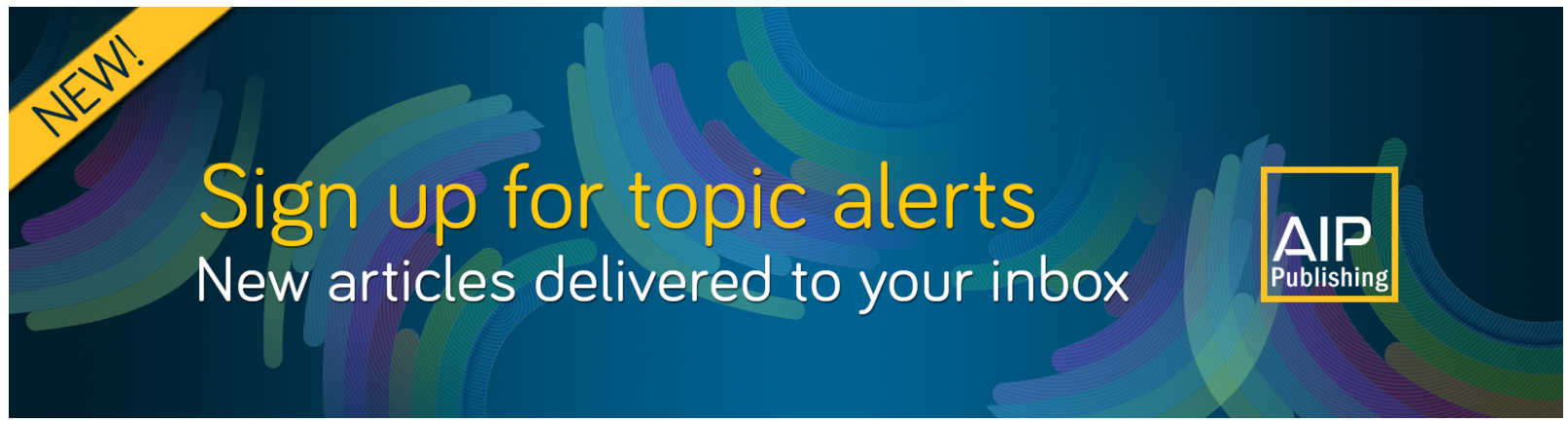




\title{
ID fluid model of RF-excited cold atmospheric plasmas in helium with air gas impurities
}

\author{
Cite as: Phys. Plasmas 27, 043512 (2020); doi: 10.1063/1.5145033 \\ Submitted: 16 January 2020 - Accepted: 21 March 2020 • \\ Published Online: 22 April 2020
}

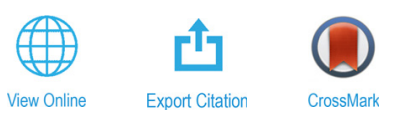

Yifan Liu, ' D Dingxin Liu, ${ }^{7, a)}$ (D) Jishen Zhang, Bowen Sun, ${ }^{7}$ (D) Aijun Yang, and Michael G. Kong ${ }^{7,2,3, b)}$

\begin{abstract}
AFFILIATIONS
'State Key Laboratory of Electrical Insulation and Power Equipment, Center for Plasma Biomedicine, Xi'an Jiaotong University, Xi'an 710049, People's Republic of China

${ }^{2}$ Frank Reidy Center for Bioelectrics, Old Dominion University, Norfolk, Virginia 23508, USA

${ }^{3}$ Department of Electrical and Computer Engineering, Old Dominion University, Norfolk, Virginia 23529, USA
\end{abstract}

a) Author to whom correspondence should be addressed: liudingxin@mail.xjtu.edu.cn

b) E-mail: mglin5g@gmail.com

\begin{abstract}
Cold atmospheric plasmas (CAPs) in helium with air gas impurities (He+Air for abbreviation) compromise the discharge stability of helium and the chemical reactivity of air, having great prospects for various applications such as plasma biomedicine. However, different kinds of reactive species are produced in He+Air CAPs but only a few of them could be measured, and the plasma chemistry is so complex that the reported simulation models are simplified to a large extent, such as neglecting the space variation of CAPs by using a 0D model. As a result, much remains unknown for He+Air CAPs, which hinders the development of their applications. For that reason, a 1D fluid model of $\mathrm{He}+$ Air CAPs is developed in this paper, incorporating 48 chemical species and 118 volume reactions, which are extracted from a complex chemistry set by a reported $0 \mathrm{D}$ model, and then the density distribution of reactive species, the power dissipation pathways, and the chemistry pathways among the reactive species are obtained as a function of air concentration from 500 to $10000 \mathrm{ppm}$. It is found that $\mathrm{O}$ and NO are the dominant reactive oxygen species (ROS) and reactive nitrogen species (RNS), respectively. Taking the ROS as a whole, it is mainly produced by the electron impact dissociation and excitation of $\mathrm{O}_{2}$; taking the RNS as a whole, it is mainly produced by the oxidation of atomic nitrogen $\left[\mathrm{N}\right.$ and $\left.\mathrm{N}\left({ }^{2} \mathrm{D}\right)\right]$, and $\mathrm{NO}$ is the precursor for all the other RNS.
\end{abstract}

Published under license by AIP Publishing. https://doi.org/10.1063/1.5145033

\section{INTRODUCTION}

Thanks to the good thermal conductivity, low breakdown voltage, and high chemical inertness, helium is commonly used as the feedstock gas of cold atmospheric plasmas (CAPs). ${ }^{1-3}$ However, a large amount of air impurity usually participates in helium CAPs, not only because the plasma reactors are typically not well sealed and even open to ambient air, but also because the air gases $\left(\mathrm{N}_{2}, \mathrm{O}_{2}, \mathrm{H}_{2} \mathrm{O}\right.$, etc.) are sometimes artificially added into helium to facilitate the production of reactive oxygen species (ROS) and reactive nitrogen species (RNS), which are deemed to be crucial for various applications. ${ }^{4-9}$ Taking the biomedical application for example, the ROS such as $\mathrm{O}$ and $\mathrm{OH}$ are strong antibacterial agents, while the RNS such as NO are known to promote and regulate wound healing. ${ }^{10-13}$ It was reported that a volume fraction of $0.5 \%-3 \%$ of air gases adding to helium CAPs could optimize the ROS and RNS production and hence be beneficial for biomedical applications. ${ }^{4,14}$ In addition, the air impurity in helium CAPs is inevitable because most of the industrial helium gas has a purity of lower than $99.999 \%$, i.e., at least 10 parts per million (ppm) of air gases exist. Since a ppm level of air gases could greatly change the reactive species produced by helium CAPs, ${ }^{15-19}$ the effect of air impurity in industrial helium could not be neglected. Above all, it is important to study the CAPs in helium with air gas impurities (He+Air for abbreviation) to elucidate the effect of air impurity on the production of ROS and RNS as well as the related biomedical applications.

$\mathrm{He}+$ Air CAPs have frequently been studied in recent years mainly by experiments. ${ }^{20-22}$ Taking the helium plasma jet for example, it was reported that the air impurity would enhance the discharge voltage, reduce the plume length, and produce more reactive species as well as increase the antimicrobial efficiency. ${ }^{4,23,24}$ However, because only a few kinds of reactive species can be measured, the concentrations of many more unmeasurable reactive species are not clear, and consequently, the chemical profile of $\mathrm{He}+$ Air CAPs has not yet been unraveled. As a result, several open questions exist such as which are 
the key reactive species for biomedical applications and how to optimize their production efficiency. ${ }^{24-28}$ This implies that a modeling study of He+Air CAPs is of importance in the current situation.

Several global models have been reported for He CAPs with air gas admixture in recent years, in which dozens of reactive species and hundreds of chemical reactions are incorporated. ${ }^{29-31}$ A global model is suitable for such chemically complex plasma because it greatly reduces the computational load with a volume-averaged assumption. However, this assumption also reduces the accuracy of simulation results. Specifically, it makes the global model impossible to obtain the spatial distribution of reactive species. Given that the spatial distribution of reactive species is strongly correlated with their wall fluxes and consequently crucial to the application efficiency, ${ }^{32}$ a spatial-resolved fluid model is required for investigating $\mathrm{He}+$ Air CAPs but so far there have been few reports. ${ }^{33}$ One problem of the fluid model is how to simplify the complex chemistry set to reduce the computational load while sustaining a reasonable simulation accuracy.

For that reason, a 1D fluid model for $\mathrm{He}+$ Air CAPs is developed in this paper, in which the chemistry set is simplified by using a global model as reported previously. ${ }^{29}$ Main reactive species and important chemical reactions are extracted from a full chemistry set to the simplified one by the global model, and this method has been successfully used for some other plasmas such as $\mathrm{He}+\mathrm{H}_{2} \mathrm{O}$ and $\mathrm{He}+\mathrm{O}_{2}$ CAPs. ${ }^{34-40}$ Based on this method, the fluid model has a reduced computational load, while it is capable of capturing the main physicochemical processes of $\mathrm{He}+\mathrm{Air}$ CAPs as validated by experiments. It should be noted that the $\mathrm{He}+$ Air CAPs studied here have a plane-parallel electrode structure and a radio frequency of $13.56 \mathrm{MHz}$. Such an electrode structure and discharge frequency are not common for biomedical applications, but they provide a classical scenario for a $1 \mathrm{D}$ fluid model simulation of $\mathrm{He}+$ Air CAPs regarding the characteristic of reactive species for the first time. The model can be further developed for the CAPs with a more complex physical structure and lower discharge frequency, which are preferred for biomedical applications. Also, the simulation results should be useful as a reference for the applications about the main ROS and RNS as well as their chemical pathways.

In this paper, the simulation model and its experimental validation are detailed in Sec. II. Then, the spatial distributions of reactive species and power dissipation, as well as the underlying chemical profile, are provided and discussed in Sec. III. Finally, concluding remarks are given in Sec. IV.

\section{SIMULATION MODEL AND ITS EXPERIMENTAL VALIDATION}

A 1D fluid model is developed for He+Air CAPs with air concentration spanning from $500 \mathrm{ppm}$ to $10000 \mathrm{ppm}$. This model is abstracted from an actual plasma reactor, so that some simulation results could be validated by experiments.

\section{A. Experimental setup}

The schematic diagram of the experimental setup is given in Fig. 1(a). It consists of two-plane-parallel copper electrodes, connecting with the high-voltage power source and the ground, respectively. The gap between two electrodes is $2 \mathrm{~mm}$, and the radius of each electrode is $4 \mathrm{~cm}$. The radius is much larger than the gap so that it is suitable to be simulated by a 1D model. Premixed helium (purity level of $5 \mathrm{~N}$ ) and artificial air are used as the working gas. For the artificial air, a bottle of dry air is used and the gas flows through another small bottle with $200 \mathrm{ml}$ de-ionized water, after that the air gas contains water vapor of around $1 \%$ in volume. In the experiments, the total gas flow rate of the helium and air is 3 SLM (standard liter per minute), in which the air concentration varies from $600 \mathrm{ppm}$ to $10000 \mathrm{ppm}$. The gas flow rates of helium and air are controlled by mass flow controllers (MFCs). It should be noted that the lowest air concentration in the model is $500 \mathrm{ppm}$, which could not be realized by experiments due to the limit of the parameter range of the MFCs.

The plasma is driven by a sinusoidal voltage with a radio frequency of $13.56 \mathrm{MHz}$. The input power density is set to be $20 \mathrm{~W} / \mathrm{cm}^{3}$ in most cases, and it is also regulated from $15 \mathrm{~W} / \mathrm{cm}^{3}$ to $26 \mathrm{~W} / \mathrm{cm}^{3}$ to (a)

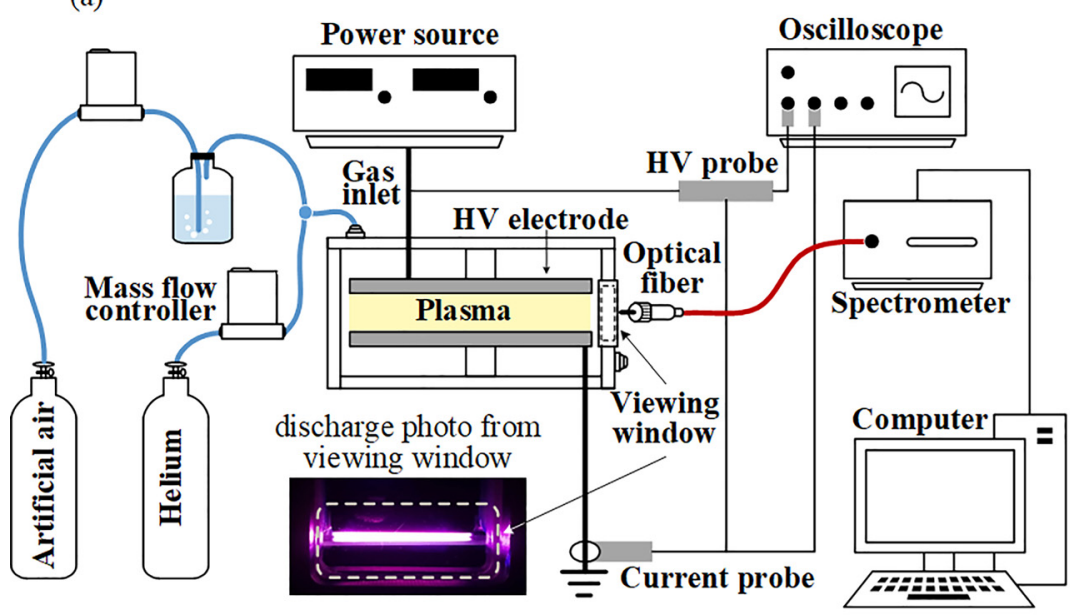

(b)

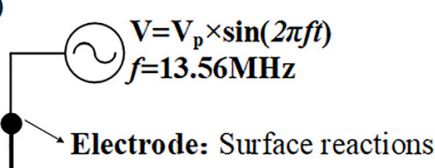

Electrode: Surface reactions

\begin{tabular}{|c|c|}
\hline Plasma & $\begin{array}{l}\text { Working gas: } \\
\mathrm{He}+\mathrm{Air} \\
\left(\mathrm{N}_{2} / \mathrm{O}_{2} / \mathrm{H}_{2} \mathrm{O}=79 / 20 / 1\right)\end{array}$ \\
\hline & $\begin{array}{l}48 \text { Species } \\
118 \text { Reacions }\end{array}$ \\
\hline
\end{tabular}

Electrode: Surface reactions

FIG. 1. Schematic diagram of (a) the experimental setup and (b) the corresponding simulation model. 
test the dependence of discharge voltage on the power density. The applied voltage and discharge current are measured by using a highvoltage probe (Tektronix P6015A) and a current probe (Pearson 2877), respectively. The emission spectra of the plasmas are measured by an optical emission spectrometer (Andor, SR750), for which the optical fiber is put outside the observation window of discharge chamber and pointed to the center region of the discharge gap. The spectral range is between $300 \mathrm{~nm}$ and $800 \mathrm{~nm}$, and the spectral resolution is $0.015 \mathrm{~nm}$. The emission spectral bands of $\mathrm{N}_{2}\left(\mathrm{C} 3 \Pi_{\mathrm{g}}-\mathrm{B} 3 \Pi_{\mathrm{g}}\right)$ in the range of $352-358 \mathrm{~nm}$ are then used to obtain the rotational temperature of $\mathrm{N}_{2}\left(\mathrm{C} 3 \Pi_{\mathrm{g}}-\mathrm{B} 3 \Pi_{\mathrm{g}}\right)$, approximately the gas temperature of the plasma, by using the software namely SPECAIR. ${ }^{41}$

\section{B. Simulation model}

Corresponding to the experimental setup, the 1D fluid model has a plasma region of $2 \mathrm{~mm}$ length, with the working gas of helium and air $\left(79 \% \mathrm{~N}_{2}+20 \% \mathrm{O}_{2}+1 \% \mathrm{H}_{2} \mathrm{O}\right)$. A RF high voltage is applied on one end of the plasma region [see Fig. 1(b)], while the other end is grounded. It should be noted that the RF driving frequency and the discharge gap are much larger than the electron energy relaxation time ( $\sim \mathrm{ns})$ and length ( $\sim$ tens of micrometers), respectively. So the fluid model is suitable to be used for simulation here. ${ }^{42,43}$

The model incorporates 48 species and 118 volume reactions, among which 47 species and 111 reactions are extracted by a global model reported previously. ${ }^{29}$ The 47 species are found to be the main species in $\mathrm{He}+$ Air CAPs among the total 59 species calculated in the global model, which have larger densities than the total density of negative ions. Also, the 111 chemical reactions are found to be important for the production or reduction of those main species, extracting from the total 866 reactions in the global model. It should be noted that the main reactions are not exactly the same as those provided in Ref. 29, because the rate coefficients of some reactions are sensitive to the gas temperature, which is $300 \mathrm{~K}$ in Ref. 29. The simplification of the chemistry set greatly reduces the computational load, while maintaining high accuracy as checked by the global model. ${ }^{29}$ A similar simplification method has also been used for $\mathrm{He}+\mathrm{H}_{2} \mathrm{O}$ and $\mathrm{He}+\mathrm{O}_{2}$ plasmas. For more details, please refer to Refs. 34-40.

In addition to the main species and reactions mentioned above, a radiative species $\mathrm{OH}(\mathrm{A})$ and its corresponding seven reactions are added to the chemistry set, because $\mathrm{OH}(\mathrm{A})$ can be easily measured for experimental validation. The emission spectral intensity at $308.9 \mathrm{~nm}$ reflects the relative density of $\mathrm{OH}(\mathrm{A})$, which can be used to compare with the simulation results for validation. All the species incorporated in the model are listed in Table I, and all the reactions as well as their rate coefficients are listed in Table II in the Appendix. The rate coefficients for most of the electron-impact reactions are calculated by using their cross sections with the assumption of Maxwellian electron energy distribution, as described in Ref. 29. This assumption would lead to some calculation errors, but it is capable of capturing the main physicochemical features of $\mathrm{He}+$ Air CAPs with much lower computational load. ${ }^{44}$

The model solves the mass conservation equation [Eq. (1)] with drift-diffusion approximation for each species, the electron energy conservation equation [Eq. (2)] and the Poisson's equation [Eq. (3)], as given by ${ }^{36,45}$
TABLE I. List of species in the model.

\begin{tabular}{|c|c|}
\hline Type & Species \\
\hline $\begin{array}{l}\text { Positive-charged } \\
\text { species }\end{array}$ & $\begin{array}{c}\mathrm{N}^{+}, \mathrm{N}_{2}{ }^{+}, \mathrm{N}_{3}{ }^{+}, \mathrm{N}_{4}^{+}, \mathrm{O}^{+}, \mathrm{O}_{2}^{+}, \mathrm{O}_{4}^{+}, \mathrm{NO}^{+}, \\
\mathrm{NO}_{2}^{+}, \mathrm{OH}^{+}, \mathrm{H}_{2} \mathrm{O}^{+}, \mathrm{H}_{3} \mathrm{O}^{+}\end{array}$ \\
\hline $\begin{array}{l}\text { Negative-charged } \\
\text { species }\end{array}$ & $\begin{array}{c}\mathrm{e}, \mathrm{O}^{-}, \mathrm{O}_{2}^{-}, \mathrm{O}_{3}^{-}, \mathrm{NO}^{-}, \mathrm{NO}_{2}^{-}, \mathrm{NO}_{3}^{-}, \\
\mathrm{OH}^{-}, \mathrm{H}^{-}\end{array}$ \\
\hline Metastables & $\begin{array}{c}\mathrm{He}^{*}, \mathrm{He}_{2}{ }^{*}, \mathrm{~N}\left({ }^{2} \mathrm{D}\right), \mathrm{N}_{2}(\mathrm{~A}), \mathrm{N}_{2}(\mathrm{~B}) \\
\mathrm{O}\left({ }^{1} \mathrm{D}\right), \mathrm{O}_{2}(\mathrm{a}), \mathrm{OH}(\mathrm{A})\end{array}$ \\
\hline Grounded neutrals & $\begin{array}{c}\mathrm{He}, \mathrm{N}_{2}, \mathrm{O}_{2}, \mathrm{H}_{2} \mathrm{O}, \mathrm{H}, \mathrm{N}, \mathrm{O}, \mathrm{O}_{3}, \mathrm{NO}, \mathrm{N}_{2} \mathrm{O}, \\
\mathrm{NO}_{2}, \mathrm{NO}_{3}, \mathrm{~N}_{2} \mathrm{O}_{5}, \mathrm{H}_{2}, \mathrm{OH}, \mathrm{HO}_{2}, \\
\mathrm{H}_{2} \mathrm{O}_{2}, \mathrm{HNO}_{2}, \mathrm{HNO}_{3}\end{array}$ \\
\hline
\end{tabular}

$$
\begin{gathered}
\frac{\partial n_{i}}{\partial t}+\nabla \cdot \boldsymbol{\Gamma}_{i}=S_{i} \boldsymbol{\Gamma}_{i}=\operatorname{sgn}\left(q_{i}\right) n_{i} \mu_{i} \mathbf{E}-D_{i} \nabla n_{i}, \\
\frac{\partial n_{\varepsilon} \varepsilon}{\partial t}+\nabla \cdot\left(\frac{5}{3} \varepsilon \boldsymbol{\Gamma}_{e}-\frac{5}{3} n_{e} D_{e} \nabla \varepsilon\right) \\
=-e \boldsymbol{\Gamma}_{e} \cdot \mathbf{E}-\sum_{j} \Delta E_{j} R_{j}-\sum_{k} 3 \frac{m_{e}}{m_{k}} R_{e l, k} k_{B}\left(T_{e}-T_{k}\right), \\
\varepsilon_{0} \nabla \cdot \mathbf{E}=\sum_{i} q_{i} n_{i},
\end{gathered}
$$

where the subscripts $e$ represents the electrons, k represents working gas ( $\mathrm{He}, \mathrm{N}_{2}, \mathrm{O}_{2}$, and $\mathrm{H}_{2} \mathrm{O}$ ), and $i$ and $j$ represent the $i_{\text {th }}$ species and $j_{\text {th }}$ reactions, respectively. The symbols $n, \Gamma, S, \mathrm{~m}, \mu$, and $D$ are density, flux, gain/loss rate, mass, drift coefficient, and diffusion coefficient, respectively. $\mathrm{E}$ is the electric field, $\Delta E$ is the electron energy loss of inelastic collision, $\mathrm{R}$ is the reaction rate, and $R_{e l}$ is the momentum transfer collisional rate between electrons and the working gas. $\varepsilon$ is the mean electron energy, $\mathrm{T}$ is the temperature, $k_{\mathrm{B}}$ is the Boltzmann constant, and $q_{i}$ is the charge of species $i$. For more details of these governing equations, please refer to our previous publications. ${ }^{36,37}$ It is worth noting that the gas temperature equation is not solved here. Instead, the gas temperature is set to be $360 \mathrm{~K}$, which is estimated by the rotational temperature obtained from the emission spectra of $\mathrm{N}_{2}(\mathrm{C}$ ) (will be discussed below).

The boundary conditions of the electrons, the positive ions, the negative ions, and the neutral species are given in Eqs. (4)-(7), respectively.

$$
\begin{gathered}
\boldsymbol{\Gamma}_{\mathrm{e}} \cdot \mathbf{n}=-a \mu_{e} \mathbf{E} \cdot \mathbf{n} n_{e}+\frac{1}{4} v_{t h, e} n_{e}-\sum_{i} \gamma_{i} \boldsymbol{\Gamma}_{\mathrm{i}}, \\
\boldsymbol{\Gamma}_{+} \cdot \mathbf{n}=a \mu_{+} \mathbf{E} \cdot \mathbf{n} n_{+}+\frac{1}{4} v_{t h,+} n_{+}, \\
\boldsymbol{\Gamma}_{-} \cdot \boldsymbol{n}=-a \mu_{-} \mathbf{E} \cdot \boldsymbol{n} n_{-}+\frac{1}{4} v_{t h,-} n_{-}, \\
\boldsymbol{\Gamma}_{\mathrm{n}} \cdot \mathbf{n}=\frac{1}{4} v_{t h, n} n_{n},
\end{gathered}
$$

where $\mathbf{n}$ is the normal vector pointing toward the electrode wall, $v_{t h}$ is the thermal velocity, $\gamma_{\mathrm{i}}$ is the secondary electron emission coefficient for $i_{\text {th }}$ heavy particles, and $a$ is a switching function as given by

$$
a= \begin{cases}1, & \operatorname{sgn}\left(q_{i}\right) \mu_{i} \mathbf{E} \cdot \boldsymbol{n}>0 \\ 0, & \operatorname{sgn}\left(q_{i}\right) \mu_{i} \mathbf{E} \cdot \boldsymbol{n} \leq 0\end{cases}
$$


where sgn is a sign function. For the electrons, the electrode loss consists of the drift flux, the thermal flux, and the secondary emission process. The bombardment of both positive ions and metastables on the electrodes could generate secondary electrons, ${ }^{46,47}$ and in our model, the emission coefficient $\gamma$ is set to be 0.105 for the positive ions and 0.115 for the metastables to fit the current-voltage characteristics of the experiments as will be discussed below. For the positive ions and negative ions, the electrode loss consists of the drift flux and the thermal flux, and all of them are assumed to be neutralized. For the neutral species, only the thermal flux is taken into account, and the surface chemistry for ground neutrals is calculated. ${ }^{38}$ These boundary conditions are similar to the previous works as detailed in Refs. 34 and 36.

The electron energy flux to the electrodes is given by

$$
\boldsymbol{\Gamma}_{\varepsilon} \cdot \mathbf{n}=\frac{5}{3}\left(\frac{1}{4} \varepsilon n_{e} v_{t h, e}-\varepsilon_{r} \sum \gamma_{i} \boldsymbol{\Gamma}_{i} \cdot \mathbf{n}\right),
$$

where $\varepsilon_{\gamma}$ is the energy of secondary electron emitted from the electrodes, which is fixed at $5 \mathrm{eV}$. ${ }^{48}$

All equations described above are solved by using the mathematics module of a time-dependent finite-element partial differential equation solver, COMSOL Multiphysics ${ }^{\circledR}$. The total number of mesh elements is 155 . The mesh size has a minimal value of $60 \mathrm{~nm}$ adjacent to the electrodes, and it has a growth rate of 1.1 toward the central part of the plasma. The simulation program is executed in a Dell OptiPlex 7050 desktop (CPU: i7-7700 $3.60 \mathrm{GHz}$, RAM size: $24 \mathrm{G}$ ). When the phase-averaged density of any reactive species changes less than $0.05 \%$ between two adjacent voltage cycles, the simulation is regarded to be in steady state. Generally, the steady state is achieved after approximately 5000 cycles, which would take at least one week for each case of calculation. The simulation results are post-processed with MATLAB ${ }^{\circledR}$.

\section{Experimental validation}

With the experimental setup, the applied voltage, discharge current, and emission spectrum of the He+Air CAPs are measured, for the purpose of (1) validating the simulation results and (2) improving some parameter settings of the model such as the secondary emission coefficient $\gamma$ and the gas temperature.
Figure 2 compares the current-voltage characteristics obtained by simulation and experiments. When the air concentration is $5000 \mathrm{ppm}$ and the discharge power density is $20 \mathrm{~W} / \mathrm{cm}^{3}$, the voltage waveforms obtained by simulation and experiment are similar, so do the current waveforms [see Fig. 2(a)]. All the waveforms have a sinusoidal shape, and the phase difference between voltage and current is around $46^{\circ}$. This similarity is also valid when the air concentration and/or the power density are changed to some extent. As shown in Fig. 2(b), the RMS voltages obtained by simulations and experiments keep increasing with the air concentration from $500 \mathrm{ppm}$ to $10000 \mathrm{ppm}$ when the power density is constant to be $20 \mathrm{~W} / \mathrm{cm}^{3}$, and the numerical difference between them is smaller than 3.6\%. As shown in Fig. 2(c), the RMS voltages obtained by simulation and experiments keep increasing with the power density from $15 \mathrm{~W} / \mathrm{cm}^{3}$ to $26 \mathrm{~W} / \mathrm{cm}^{3}$ when the air concentration is constant to be $5000 \mathrm{ppm}$, and the numerical difference between them is no more than $3.8 \%$. These results indicate that the numerical model is capable of obtaining the current-voltage characteristics of the $\mathrm{He}+$ Air CAPs with a high accuracy.

Figure 3(a) shows the emission spectrum of the He+Air CAP with an air concentration of $5000 \mathrm{ppm}$ and a power density of $20 \mathrm{~W} /$ $\mathrm{cm}^{3}$. Hereafter the power density is always $20 \mathrm{~W} / \mathrm{cm}^{3}$. In the spectrogram, the $\mathrm{OH}$ band (306-312 nm), $\mathrm{N}_{2}$ bands [306-391 nm for $\mathrm{N}_{2}\left(\mathrm{C}^{3} \Pi_{\mathrm{u}}-\mathrm{B}^{3} \Pi_{\mathrm{g}}\right)$ and $540-770 \mathrm{~nm}$ for $\left.\mathrm{N}_{2}\left(\mathrm{~B}^{3} \Pi_{\mathrm{g}}-\mathrm{A}^{3} \Sigma_{\mathrm{u}}{ }^{+}\right)\right], \mathrm{N}_{2}{ }^{+}$band [385-460 nm for $\mathrm{N}_{2}{ }^{+}\left(\mathrm{B}^{2} \Sigma_{\mathrm{u}}{ }^{+}-\mathrm{X}^{2} \Sigma_{\mathrm{g}}{ }^{+}\right)$], and helium lines are clearly identified, similar to the results reported in Ref. 49-52. For the $\mathrm{He}+$ Air CAPs with air concentrations of $600,1000,2000,5000$, and $10000 \mathrm{ppm}$, the $\mathrm{N}_{2}\left(C^{3} \Pi_{\mathrm{g}}-\mathrm{B}^{3} \Pi_{\mathrm{g}}\right)$ emission spectra in the wavelength range between 352 and $358 \mathrm{~nm}$ are compared with the theoretical spectra simulated by SPECAIR at different rotational temperatures. ${ }^{41}$ The best fit is found to be $\sim 360 \mathrm{~K}$ for all the cases of air concentrations, and thus, it is set to be the gas temperature in the model because the gas temperature is approximately equivalent to the rotational temperature for atmospheric discharge. ${ }^{53}$ In addition, the variation trends of emission intensities of $\mathrm{OH}(\mathrm{A})$ and $\mathrm{N}_{2}(\mathrm{~B})$ are shown in Figs. 3(b) and $3(\mathrm{C})$, as a function of the air concentration.

The emission intensity could reflect the relative density of a specific radiative species, so the variation trends are used to compare with the simulation results of $\mathrm{OH}(\mathrm{A})$ and $\mathrm{N}_{2}$ (B) densities for validation. As shown in Fig. 3(b), both experimental and numerical results have
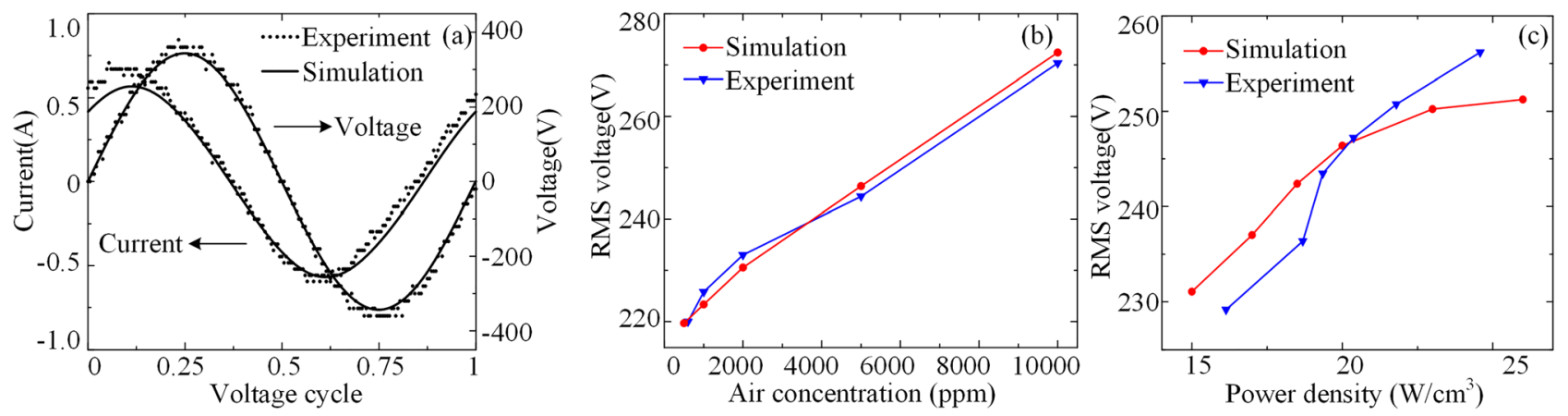

FIG. 2. Comparison of the simulation and experimental results of applied voltage and discharge current. (a) The typical waveforms of applied voltage and discharge current for the power density of $20 \mathrm{~W} / \mathrm{cm}^{3}$ and air concentration of $5000 \mathrm{ppm}$. (b) The dependence of RMS voltages on the air concentration. (c) The dependence of RMS voltages on the input power density. 

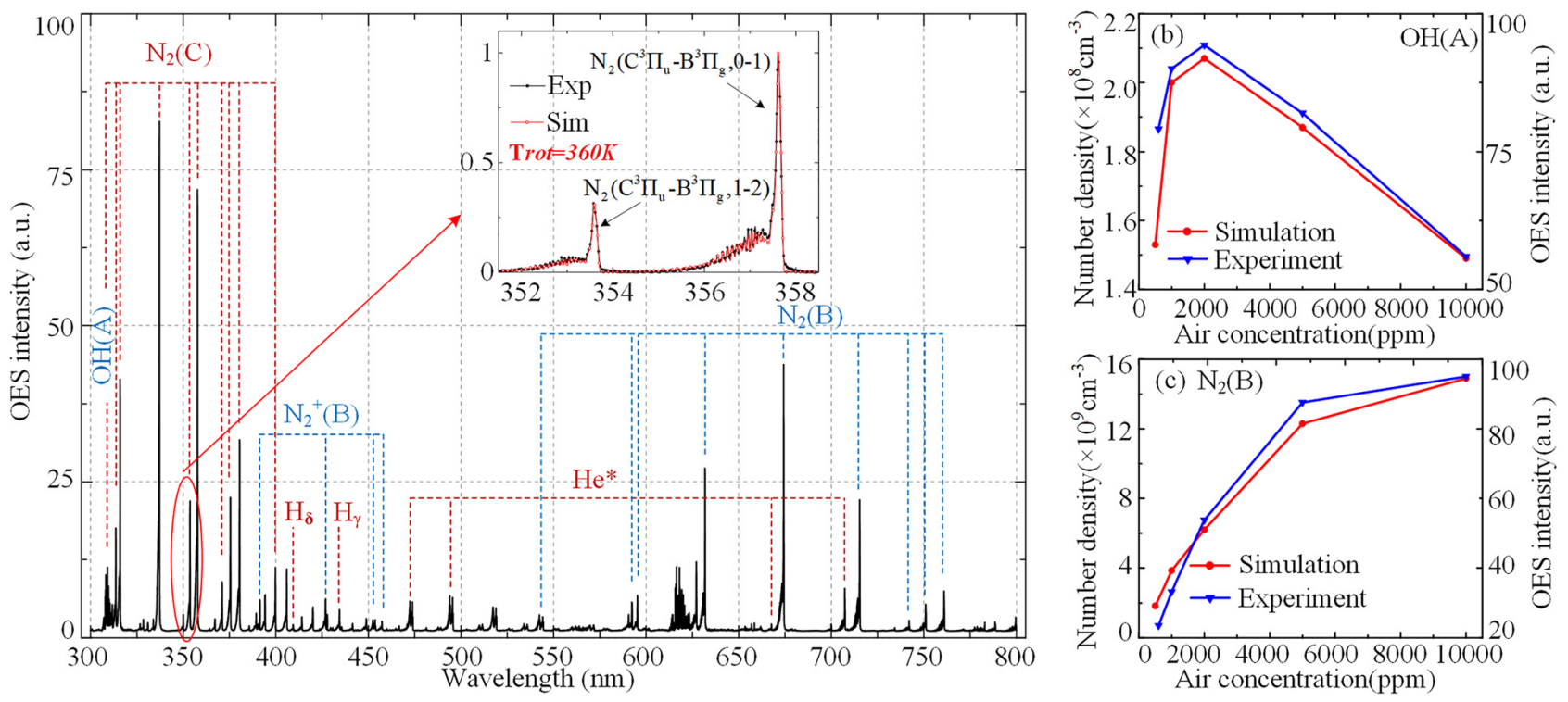

FIG. 3. Comparison of the simulation and experimental results of relative densities of radiative species. (a) The emission spectrum of the He+Air CAP (20 W/ $\left.\mathrm{cm}^{3}, 5000 \mathrm{ppm}\right)$. (b) The variation trends of the average density obtained by simulation and the emission intensity obtained by experiments of $\mathrm{OH}(\mathrm{A})$. (c) The variation trends of the average density obtained by simulation and the emission intensity obtained by experiments of $\mathrm{N}_{2}(B)$.

similar trends of first increasing and then decreasing, peaking at [air] $\sim 2000 \mathrm{ppm}$. This indicates that the density of $\mathrm{OH}(\mathrm{A})$ maximizes at [air] $\sim 2000 \mathrm{ppm}$. Only the start points of the experimental and numerical curves in Fig. 3(b) have a relatively large discrepancy. One reason is that the simulation starts at $[\mathrm{air}]=500 \mathrm{ppm}$, but the experiments start at [air] $=600 \mathrm{ppm}$ due to the limit of parameter range of the MFCs. Another reason is that the gas impurity in the industrial helium, larger than $10 \mathrm{ppm}$, has some impact on the experimental results, which might be pronounced when the air concentration is low. Different to $\mathrm{OH}(\mathrm{A})$, the emission intensity and the density of $\mathrm{N}_{2}(\mathrm{~B})$ keep increasing with the air concentration, but the growth rate decreases [see Fig. 3(c)]. This indicates that the experimental and numerical results of $\mathrm{N}_{2}(\mathrm{~B})$ have similar trends, too.

The applied voltage, the discharge current, and the density trends of $\mathrm{OH}(\mathrm{A})$ and $\mathrm{N}_{2}(\mathrm{~B})$ agree well between the numerical and experimental results, implying that our model is valid for $\mathrm{He}+$ Air CAPs to some extent. Quantitative measurement of reactive species could further validate the model; for example, the densities of $\mathrm{O}$ and $\mathrm{OH}$ could be measured by laser induce fluorescence (LIF) and then compared with the simulation results. However, we do not have the experimental condition in our laboratory at present.

\section{RESULTS AND DISCUSSION}

\section{A. Reactive species and power dissipation of the

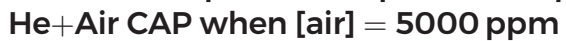

The He+Air CAP with an air concentration of $5000 \mathrm{ppm}$ is investigated here, because this concentration is reported to be optimal for producing reactive species. ${ }^{54-56}$ We focus on obtaining the density distributions of ROS and RNS because they are crucial for biomedical applications. ${ }^{57,58}$ Moreover, for the sake of elucidating why the ROS and RNS have such density distributions, the characteristics of electrons and power dissipation are also provided. This is because the
ROS and RNS are directly or indirectly produced by electrons, and the discharge power is consumed for their production.

The spatial-temporal distributions of electron density, electron temperature, density of positive ions, and electron production rate are shown in Fig. 4, in which the horizontal axis represents the gas gap between electrodes, while the vertical axis represents the time in one voltage cycle. The white curves represent the sheath boundaries with a criterion of $n_{e}=0.3\left(n_{e}-n_{a}\right)$, where $n_{c}$ and $n_{a}$ are the densities of positive and negative ions, respectively. ${ }^{34,35,59}$

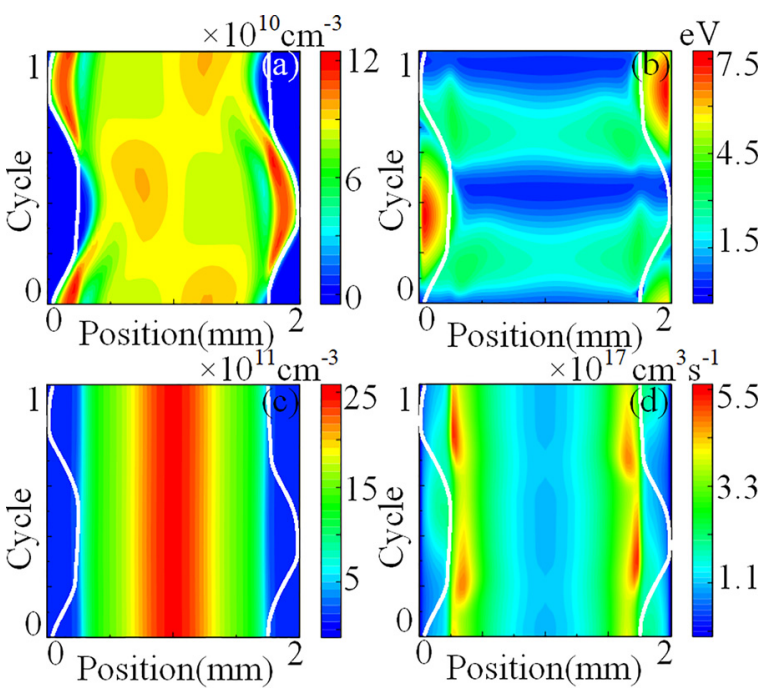

FIG. 4. Spatial-temporal distribution of (a) electron density, (b) electron temperature, (c) positive ions density, and (d) electron generation rate. The white curves represent the sheath boundaries. 
It can be seen from Fig. 4(a) that the electrons oscillate between the electrodes due to their small inertia, along with the expansion and/ or collapse of the sheath region. ${ }^{60}$ The maximal thickness of the sheath is $232 \mu \mathrm{m}$. The electron density has a peak value of $\sim 1.2 \times 10^{11} \mathrm{~cm}^{-3}$, appearing near to the edge of the sheath region and the plasma bulk. ${ }^{61}$ The spatial-temporal averaged electron density is $\sim 7.8 \times 10^{10} \mathrm{~cm}^{-3}$. During the electron oscillation, the electron density could be stratified into three regions, including the near-sheath peak region in red, the central flat region in yellow, and the local minimal region between them in green as shown in Fig. 4(a). This is a typical spatial distribution of electron density for electronegative plasmas, as reported for a $\mathrm{He}+\mathrm{H}_{2} \mathrm{O}$ CAP previously. ${ }^{62}$

The electron temperature has a peak value of $7.36 \mathrm{eV}$, appearing in the sheath region when the sheath thickness is at its maximum [see Fig. 4(b)]. Such a high electron temperature is critical for some energy-sensitive reactions, for example, the electron impact excitation of helium of which the threshold energy is $19.8 \mathrm{eV}$. The spatialtemporal averaged electron temperature is just $2.07 \mathrm{eV}$.

The spatial-temporal distribution of positive ions is shown in Fig. 4(c). In contrast to the electrons, the total density of positive ions is nearly immobile during one voltage cycle, and it peaks in the center point of the gas gap. This is attributed to the much larger inertia of cations than that of electrons. The averaged density of positive ions is $\sim 9.3 \times 10^{11} \mathrm{~cm}^{-3}$, larger than that of electrons by more than one order of magnitude. So, the He+Air CAP is a typical electronegative plasma with an electronegativity of $\sim 10.9$. Although the density distribution of negative ions is not shown here, it is similar to that of positive ions because of their large inertia, too. The density of negative ions is slightly lower than that of positive ions. However, because the moving direction forced by electric field is opposite, there are some instantaneous regions where the density of negative ions is slightly larger. As a result, the local intrinsic electric field would change its direction in some moment to impede the moving of electrons toward the anode electrode, which is the reason for the three-region stratification of electrons. $^{63}$

Regarding the production of electrons as shown in Fig. 4(d), the main pathways are the detachment of negative ions and the Penning ionization. The collisional detachment contributes $\sim 66 \%$ of the production, which has a large rate over the whole plasma bulk region. The Penning ionization accounts for $\sim 34 \%$ of the production, which peaks near to the sheath boundary [the red areas shown in Fig. 4(d)]. The electrons are mainly produced in the plasma bulk, implying that the discharge works in $\alpha$ mode in this discharge condition.

The time-averaged spatial distributions of the main ROS and RNS are shown in Figs. 5(a) and 5(b), respectively. The most abundant ROS is atomic oxygen $(\mathrm{O})$, followed by singlet oxygen $\left[\mathrm{O}_{2}(\mathrm{a})\right]$, ozone $\left(\mathrm{O}_{3}\right)$, and hydroxyl radical $(\mathrm{OH})$. The averaged densities of $\mathrm{O}$ and $\mathrm{O}_{2}$ (a) are $8.7 \times 10^{14} \mathrm{~cm}^{-3}$ and $6.2 \times 10^{14} \mathrm{~cm}^{-3}$, respectively. The radiative species $\mathrm{O}\left({ }^{1} \mathrm{D}\right)$ and the bio-active anion $\mathrm{O}_{2}{ }^{-}$have the lowest densities, on the order of $10^{11} \mathrm{~cm}^{-3}$. The time-averaged density distributions of some ROS such as $\mathrm{O}_{2}(\mathrm{a}), \mathrm{OH}$, and $\mathrm{HO}_{2}$ have a unimodal shape, similar to that of the electrons as will be shown in Fig. 7. These ROS are directly or indirectly produced by electrons, so their densities are strongly correlated with the electron density. In contrast, some other ROS including $\mathrm{O}, \mathrm{O}_{3}$, and $\mathrm{O}^{1}(\mathrm{D})$ have a bimodal shape of spatial distribution, because their production is sensitive to not only the electron density, but also the electron temperature as well. Taking
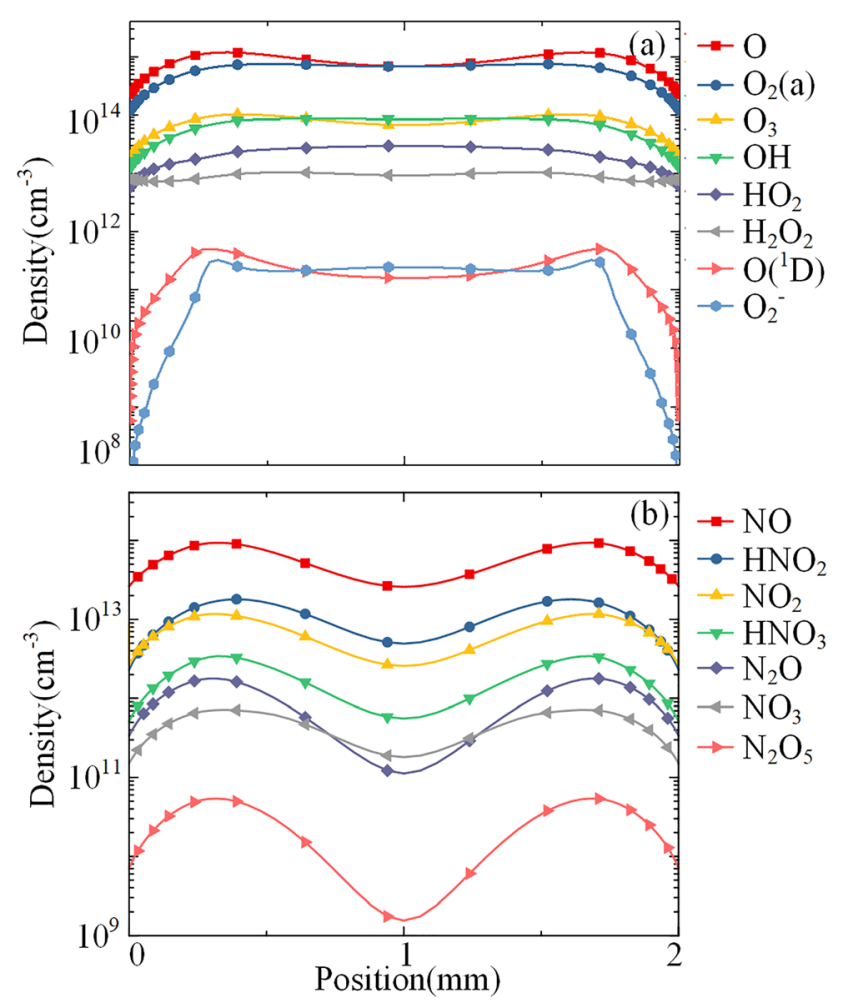

FIG. 5. Time-averaged spatial distribution of (a) ROS and (b) RNS when the air concentration is $5000 \mathrm{ppm}$ and the power density is $20 \mathrm{~W} / \mathrm{cm}^{3}$.

$\mathrm{O}_{2}$ (a) and $\mathrm{O}^{1}(\mathrm{D})$ for example, both of them are mainly produced by electron impact excitation of oxygen, but the former one needs a small energy of only $0.97 \mathrm{eV}$, while the latter one needs a much larger energy of $7.4 \mathrm{eV}$. So, the density of $\mathrm{O}_{2}$ (a) mainly depends on the electron density, but the density of $\mathrm{O}\left({ }^{1} \mathrm{D}\right)$ should be sensitive to both the electron density and the electron temperature. In addition, the density of $\mathrm{H}_{2} \mathrm{O}_{2}$ is almost constant along the gas gap, because it is generated not only in the gas gap, but also on the electrode surfaces via surface reactions. Similar to the other negative ions, the density profile of $\mathrm{O}_{2}{ }^{-}$drops sharply in the vicinity of the electrodes due to the ambipolar electric field.

Compared to the ROS, the RNS have a total density lower by approximately 20 times. NO is the most abundant RNS, followed by $\mathrm{HNO}_{2}$ and $\mathrm{NO}_{2}$. The average density of $\mathrm{NO}$ is $\sim 5.8 \times 10^{13} \mathrm{~cm}^{-3}$. $\mathrm{N}_{2} \mathrm{O}_{5}$ has the lowest density among the RNS, which is just $\sim 2 \times 10^{10} \mathrm{~cm}^{-3}$. Interestingly, all the RNS have a bimodal density profile as shown in Fig. 4(b). This is because the RNS are mainly produced by nitrogen atoms $\mathrm{N}$ and $\mathrm{N}\left({ }^{2} \mathrm{D}\right)$ as will be discussed below, and the densities of nitrogen atoms should be sensitive to both the electron density and electron temperature since they are mainly produced by electron impact dissociation and/or dissociative excitation of nitrogen.

Figure 6 shows the time-averaged spatial distribution of power dissipations including electron Joule heating and ion Joule heating, as well as the dissipation of electron Joule heating via elastic collision and inelastic collision. The ion Joule heating has little effect on the production of ROS and RNS, which is negligible in low-pressure plasmas but 


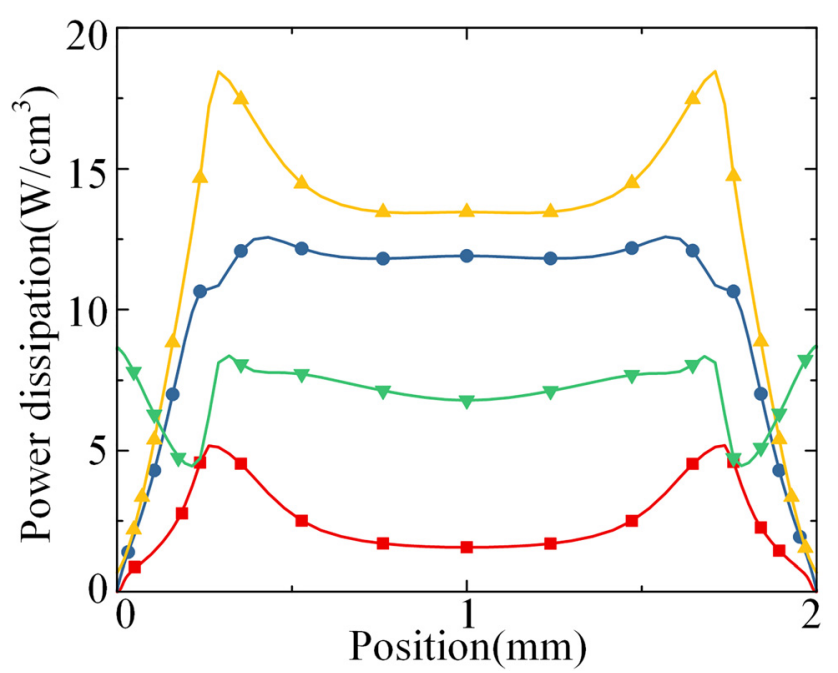

FIG. 6. Time-averaged spatial distribution of power dissipation pathways (electron Joule heating; $\boldsymbol{\nabla}$ : ion Joule heating; $-\mathbf{-}$ : elastic collision and inelastic collisions).

not the case in CAPs, especially when the CAPs are strong electronegative. $^{64,65}$ In the case of [air] $=5000$ ppm, the electron Joule heating accounts for $64 \%$ of the total power dissipation, and the ion Joule heating consumes a large portion of $36 \%$. Given that the electronegativity is $\sim 10.9$, the result of power allocation between electrons and ions agrees well with the formula proposed in Ref. 35 , as given by

$$
\eta=\frac{P_{\mathrm{e}}}{P_{i}}=\frac{\mu_{e}}{\mu_{i}(2 \alpha+1)},
$$

where $P_{e}$ is the power dissipation via electron Joule heating, $P_{i}$ is the power dissipation via ion Joule heating, $\mu_{e}$ and $\mu_{i}$ are the mobility coefficients of electron and ions, and $\alpha$ is electronegativity.

The electron Joule heating is coupled to electrons by acceleration, and then, the electrons could gain enough energy to dissociate, ionize, and/or excite heavy molecules for producing ROS and RNS. However, a large amount of electrons could only have elastic collisions with heavy molecules, with little contribution on the production of ROS and RNS but heating the heavy molecules. The input power dissipated on inelastic collisions is responsible for the production of ROS and RNS, which accounts for just $12 \%$ of the total power dissipation. As shown in Fig. 6, the power dissipation via inelastic collisions has a bimodal shape, which should be the reason why the electrons and most of the ROS and RNS have such density profiles.

\section{B. Reactive species and power dissipation of $\mathrm{He}+$ Air CAPs with varied air concentration}

In order to investigate the influence of air concentration on the reactive species and the power dissipation, the $\mathrm{He}+\mathrm{Air}$ CAPs with different air concentrations including 500, 1000, 2000, 5000, and $10000 \mathrm{ppm}$ are studied by the fluid model. The air concentration range between 500 and 10000 ppm covers most scenarios of $\mathrm{He}+\mathrm{Air}$ CAPs used for biomedical applications.

Figure 7 shows the time-averaged spatial distribution of the electron density, the electron temperature, the density of positive ions, the
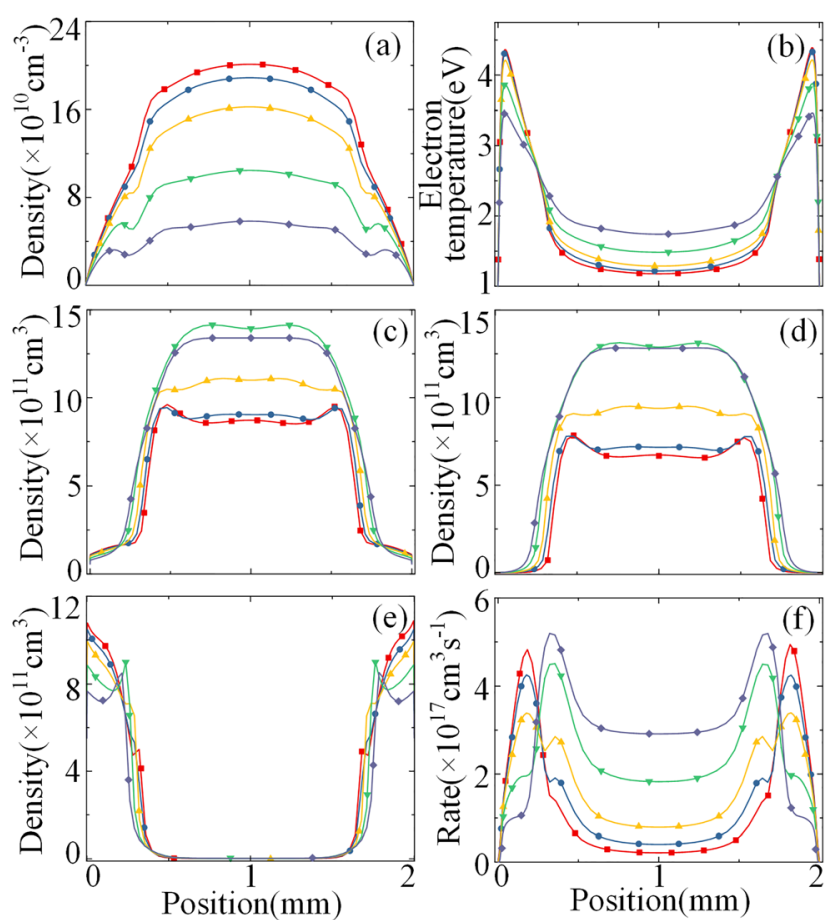

FIG. 7. Time-averaged spatial distributions of (a) the electron density, (b) the electron temperature, (c) the density of positive ions, (d) the density of negative ions, (e) the density of net charge, and ( $f$ ) the total rate of electron generation for different air concentrations $(-[500 \mathrm{ppm},-1000 \mathrm{ppm},-2000 \mathrm{ppm}, \boldsymbol{-}$ $5000 \mathrm{ppm}$, and $-10000 \mathrm{ppm})$.

density of negative ions, the density of net charge, and the total generation rate of electrons. The density of net charge equals to the density of positive charge minus the density of negative charge (electrons and negative ions). With the increasing air concentration from 500 to $10000 \mathrm{ppm}$, the electronegativity of $\mathrm{He}+$ Air CAPs increases from 3.0 to 19.6. Since more electrons are consumed by electron attachment reactions, the averaged electron density decreases from $1.5 \times 10^{11}$ to $4.4 \times 10^{10} \mathrm{~cm}^{-3}$ [see Fig. 7(a)]. The density profile of electrons declines monotonically as closing to the electrodes when [air] $\leq 1000 \mathrm{ppm}$, but it has a small peak in the vicinity of each electrode when [air] $>1000 \mathrm{ppm}$. This indicates the stratification structure of the electron profile as discussed in Fig. 4.

For all the air concentrations, the electron temperature profiles are similar, which have a peak shape in each sheath region and a flattened shape in plasma bulk, as shown in Fig. 7(b). With the increasing air concentration, the spatial-temporal averaged electron temperature increases from 1.91 to $2.19 \mathrm{eV}$. This is because the electron temperature in plasma bulk increases to compensate the decreasing electron density for sustaining the discharge current. In the meantime, the maximum value of electron temperature in the sheath region decreases from 10.0 to $6.32 \mathrm{eV}$. Owing to the increasing electronegativity, the ion flux accounts more for the current in sheath. The ion flux has less correlation with the strong electric field than that of the electron flux, leading to the decrease in electron temperature there. The increasing average value and decreasing peak value of electron temperature could change the main pathways for the production of ROS and RNS, as will be discussed in Fig. 9. 
As shown in Fig. 7(c), the density of positive ions increases with the air concentration when [air] $\leq 5000 \mathrm{ppm}$ and then decreases slightly. It peaks at [air] $=5000 \mathrm{ppm}$ with an average value of $9.5 \times 10^{11} \mathrm{~cm}^{-3}$. The density decrease in positive ions when [air] $>5000 \mathrm{ppm}$ is because a large amount of neutral ROS is produced, which enhances the destruction of main positive ions such as $\mathrm{O}_{4}{ }^{+}$. The spatial region of positive ions expands with the increasing air concentration, indicating that the sheath thickness contracts in the meantime. ${ }^{34}$ The maximal sheath thickness is $320 \mu \mathrm{m}$ when [air] $=500 \mathrm{ppm}$, but it gradually reduces to $195 \mu \mathrm{m}$ when [air] $=10000 \mathrm{ppm}$. The density profiles of negative ions are similar to those of the positive ions, as shown in Fig. 7(d). Also, the average density of negative ions has a similar tendency of first increasing and then decreasing slightly as a function of the air concentration. The differences are that the negative ions are more confined in the central part due to the ambipolar field, and the density value of negative ions is relatively low. The peak average density of negative ions is $8.5 \times 10^{11} \mathrm{~cm}^{-3}$ at [air] $=5000 \mathrm{ppm}$. For the spatial distribution of net charge as shown in Fig. 7(e), the quasi-neutrality is sustained in the bulk region regardless of the air concentration. In the sheath region, it is interesting that the double-hump structure is formed when [air] $\geq 5000 \mathrm{ppm}$, which is consistent with the stratification of electron density as given in Fig. 7(a).

With the increasing air concentration, the electron generation rate keeps decreasing in the sheath region while increasing in the bulk region, as shown in Fig. 7(f). The profile of the electron generation rate has two peaks when [air] $=500 \mathrm{ppm}$, and each of them has a distance of $\sim 150 \mu \mathrm{m}$ from the adjacent electrode. These two peaks decline with the increasing air concentration, and when [air] $=1000 \mathrm{ppm}$ another two peaks appear, each of which has a distance of $\sim 400 \mu \mathrm{m}$ from the adjacent electrode. The outside peaks keep declining and even disappear when [air] $\geq 5000 \mathrm{ppm}$, while the inside peaks keep rising. Besides, the electron generation rate in the center part of the gas gap, shown as a flattened shape in Fig. 7(f), also keeps increasing with the air concentration. As a result, the discharge mode transfers from $\gamma$ mode to $\alpha$ mode with a threshold air concentration of $\sim 2000 \mathrm{ppm}$. Two pathways are most responsible for the electron generation: one is the Penning ionization and the other is the detachment of negative ions. Penning ionization mainly happens in the neighborhood of the sheath boundary, which is responsible for the production of the outside peaks in the profile of the electron generation rate. Detachment of negative ions mainly happens in the center part because most of the negative ions are confined there, and it is responsible for the production of the inside peaks in the profile of electron generation rate when [air] $\geq 2000 \mathrm{ppm}$. With the increasing air concentration, the dominant electron generation pathway converts from the Penning ionization to the detachment of negative ions, which is the reason for the discharge mode transition from $\gamma$ mode to $\alpha$ mode. $^{66}$

The influence of air concentration on the spatial-temporal averaged densities of ROS and RNS is shown in Fig. 8. O is the dominant ROS in all the cases of air concentration, followed by $\mathrm{O}_{2}(\mathrm{a}), \mathrm{OH}$, and $\mathrm{O}_{3}$. These four ROS have their densities increasing almost linearly with the air concentration. Taking $\mathrm{O}$ for instance, its density increases from $10^{14}$ to $10^{15} \mathrm{~cm}^{-3}$ with the increasing air concentration from 500 to $10000 \mathrm{ppm}$. The densities of some other ROS including $\mathrm{HO}_{2}$, $\mathrm{H}_{2} \mathrm{O}_{2}$, and $\mathrm{O}^{1}(\mathrm{D})$ also increase with the air concentration, except for $\mathrm{O}_{2}{ }^{-} \cdot \mathrm{O}_{2}{ }^{-}$has a strong charge transfer reaction with $\mathrm{O}$, so its density
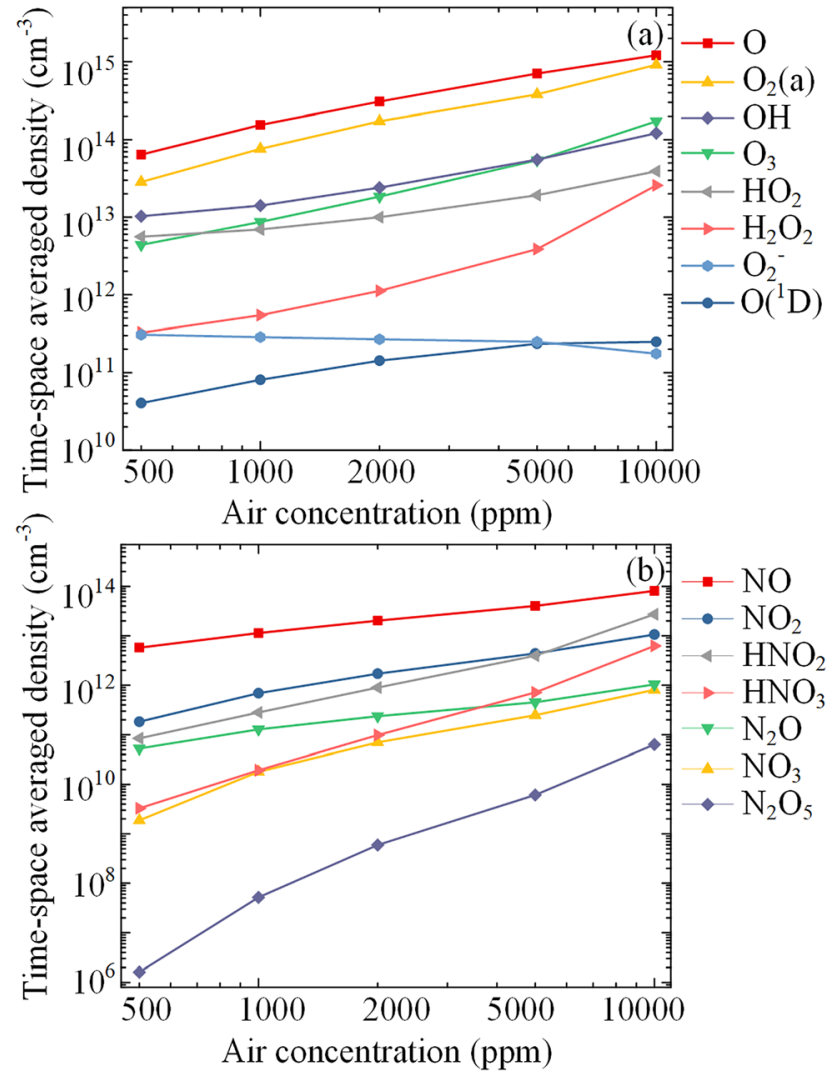

FIG. 8. Spatial-temporal averaged densities of (a) ROS and (b) RNS as a function of air concentration.

decreases with the increasing density of $\mathrm{O}$. Regarding the RNS, NO is the most abundant species in all the cases of air concentration, followed by $\mathrm{NO}_{2}$ and $\mathrm{HNO}_{2}$. All the RNS have their densities increasing with the air concentration. Taking NO for example, its concentration increases from $10^{13}$ to $10^{14} \mathrm{~cm}^{-3}$ with the increasing air concentration from 500 to $10000 \mathrm{ppm}$. The density of NO is higher than that of the other RNS by more than one order of magnitude when [air] $\leq 5000 \mathrm{ppm}$. Compared to that of the ROS, the total density of RNS is lower by $\sim 20$ times for all the cases of air concentration, implying that $\mathrm{He}+$ Air CAPs are preferable for the applications where ROS are mostly required. Compared to the air plasma in which $\mathrm{O}_{3}$ and $\mathrm{N}_{2} \mathrm{O}_{5}$ are the dominant ROS and RNS, ${ }^{67}$ the $\mathrm{He}+$ Air CAPs have much different chemical products, indicating that the biomedical effect of these two kinds of plasmas would be much different. In addition, it can be seen from Fig. 8 that the production efficiency of ROS and RNS has not yet been optimized in the studied range of air concentration. Increasing the air concentration above $1 \%$ would further enhance the production efficiency of ROS and RNS, but in turn it would severely decrease the plasma stability. It is not easy to control the He+Air CAPs to keep diffusive when the air concentration is larger than $1 \%$.

In order to further unravel the production mechanism of ROS and RNS from the perspective of power consumption, the power dissipation pathways are illustrated in Fig. 9 as a function of the air concentration. It can be seen that the power dissipation on ions (ion Joule 

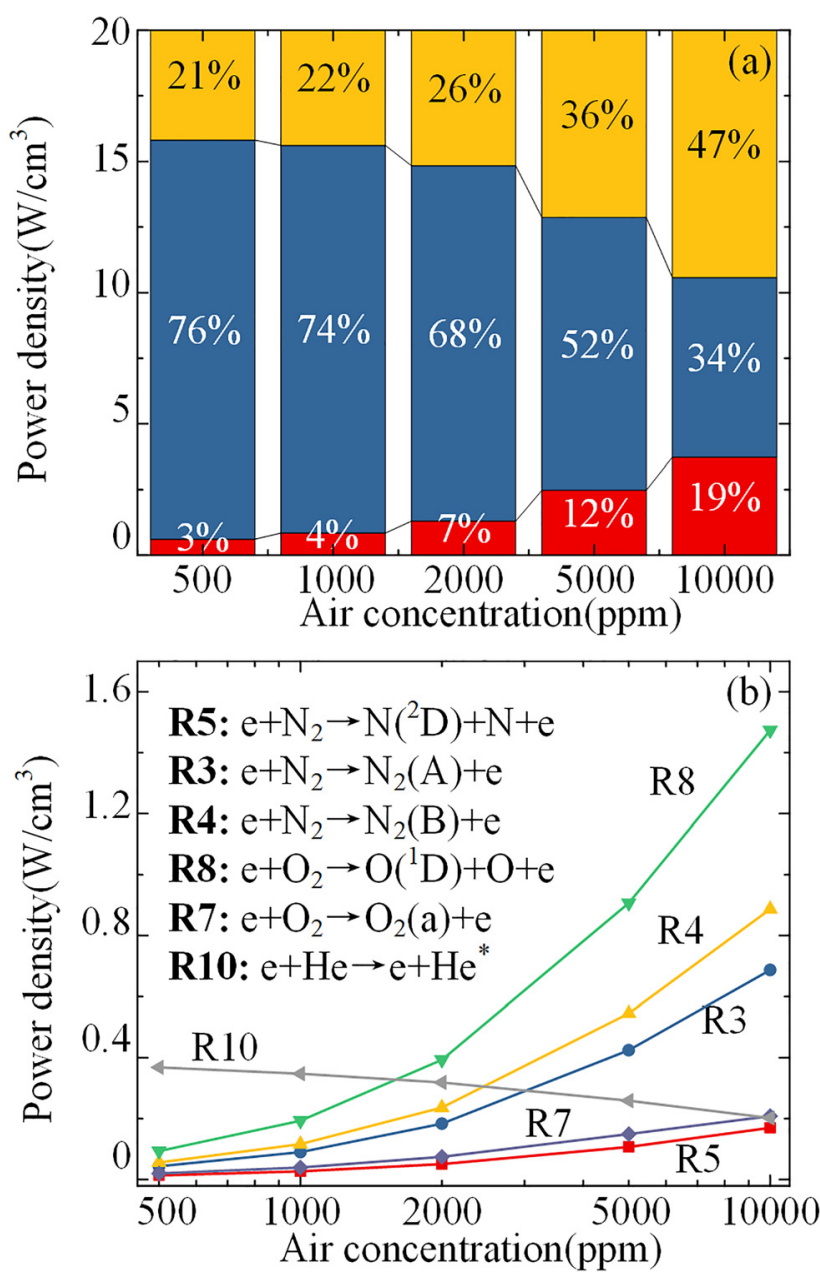

FIG. 9. (a) Variation of power dissipation by ion Joule heating (yellow), elastic collisions (blue), and inelastic collisions (red) as a function of air concentration. (b) Power consumption by several inelastic collisions as a function of air concentration.

heating) increases from $21 \%$ to $47 \%$ of the total input power with the increasing air concentration from 500 to $10000 \mathrm{ppm}$. Even at a low air concentration of $500 \mathrm{ppm}$, the ion Joule heating accounts for a large portion of the discharge power, much different to that in low-pressure plasmas. ${ }^{64}$ The amount of ions increases while the amount of electrons decreases with the increasing air concentration (see Fig. 7), so it is certain that more power would dissipate on ions. The power allocation between electrons and ions can be roughly estimated by formula (10). Besides the ion Joule heating, the electron Joule heating is a main power dissipation pathway, which could be divided into elastic collisions and inelastic collisions as shown in Fig. 9(a). It can be seen that the power dissipation on inelastic collisions increases fast from $3 \%$ to $19 \%$ of the total input power. Two reasons may account for such a sharp increase: (1) the molecular air gases have larger inelastic collision cross sections but lower elastic collision cross sections compared to helium and (2) the average electron temperature increases, which facilitates the inelastic collisions.
The power dissipation on inelastic collisions is strongly correlated with the production of ROS and RNS, so the main reactions for such power dissipation are important and hence illustrated in Fig. 9(b) as a function of air concentration. The reaction numbers are the same as in Table II in the Appendix. It can be seen that all the main reactions for power dissipation are electron impact excitation and/or dissociative excitation. Other kinds of reactions such as ionization and dissociation consume little power. The electron impact excitation of helium (R10) dominates the power dissipation when [air] $<2000$ ppm, but the power coupled to R10 keeps decreasing. Since helium density is almost constant, the reaction rate of R10 depends on the density of energetic electrons, which have energies of no less than $19.8 \mathrm{eV}$. However, both the electron density and the peak electron temperature decrease with the increasing air concentration (see Fig. 7), so the power dissipation on R10 keeps decreasing. The density of helium metastable decreases in consequence, which accounts for the decrease in Penning ionization on the production of electrons (see Fig. 7). In contrast to R10, the other reactions consume more and more power with the increasing air concentration, because the increasing air gases are the reactants. However, the dissipation powers via the reactions except for R10 increase slower than the air concentration due to the decrease in electron density.

The wall fluxes may be a general indicator for how strong the plasma species impact samples to be treated in applications. However, the wall fluxes of reactive species are hard to be measured, so their relative magnitudes are usually estimated by comparing their average densities. This estimation is acceptable for long-lived species because these species could pass through the gas gap in their lifetimes, i.e., all the species distributed in the plasma could possibly contribute on the wall flux. However, for the short-lived species which could not pass the gas gap during their lifetimes, the spatial-averaged densities might have little correlation with the wall fluxes. ${ }^{37}$ Taking a short-lived species, $\mathrm{O}\left({ }^{1} \mathrm{D}\right)$ in $\mathrm{He}+\mathrm{O}_{2}$ CAPs for example, it was reported that the wall flux has a different variation trend to the spatial-averaged density, because only the $\mathrm{O}\left({ }^{1} \mathrm{D}\right)$ existing in the vicinity of the electrodes could move on the electrodes before its chemical conversion.

In order to determine whether the average density of a shortlived species can be used to estimate its relative electrode flux in the $\mathrm{He}+$ Air CAPs, the spatial-temporal averaged density and the timeaveraged electrode flux of several ions are comparatively shown in Fig. 10 as a function of air concentration. Generally, it can be seen that the average densities decrease with the increasing air concentration, while in contrast the electrode fluxes keep increasing. The opposite trend between the density and flux is interesting, indicating that one should be careful to use the average density of a species to estimate its flux.

\section{Production mechanism of reactive species in He+Air CAPs}

Understanding of the production mechanism of ROS and RNS in $\mathrm{He}+\mathrm{Air}$ CAPs would give an opportunity to find the optimal discharge condition for applications. For this reason, we plot in Fig. 11 the main production/destruction pathways of bio-active ROS and RNS for such plasmas with a varied air concentration from 500 to $10000 \mathrm{ppm}$. All the ROS are categorized in a yellow dash box located in the left side of the figure, all the RNS are categorized in a blue dash box in the right side, and each ROS or RNS is shown in a small light 

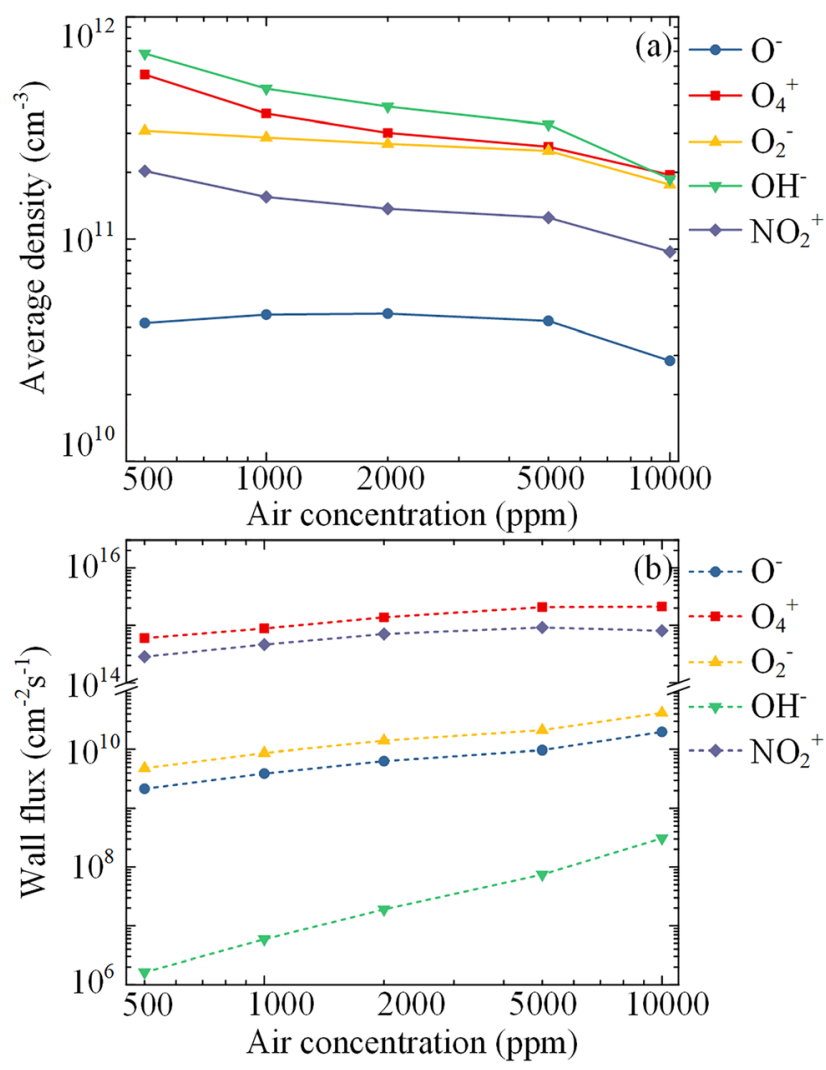

FIG. 10. (a) Spatial-temporal averaged density and (b) time-averaged wall fluxes of several ions as a function of air concentration.

red box. The red arrows pointing into each light red box indicate the production reactions of the corresponding reactive species, while the blue arrows pointing outside each box indicate the destruction reactions. Each percentage value shown in the box indicates the contribution of the production/destruction pathway to the total production/ destruction of the specific species as a function of air concentration from 500 to $10000 \mathrm{ppm}$. The dotted line in each arrow means that the reaction is not important, accounting for less than $10 \%$ of the total production/destruction rate of the corresponding species, so in that case the percentage value is not provided.

It can be seen from Fig. 11 that all the ROS and RNS originate from the electron impact reactions with air gases, and most of them are eventually transformed back to the air gases by their interactions. Regarding the ROS, $\mathrm{O}_{2}$ (a) is mainly generated by the electron impact excitation of $\mathrm{O}_{2}$ (R7), $\mathrm{O}_{2}{ }^{-}$is generated by the electron impact attachment of $\mathrm{O}_{2}(\mathrm{R} 15)$, and $\mathrm{O}\left({ }^{1} \mathrm{D}\right)$ is generated by the electron impact dissociative excitation of $\mathrm{O}_{2}$ (R8). Similar to that reported in Ref. 68, the ground state $\mathrm{O}$ is particular, which is generated by several reactions as follows:

$$
\begin{gathered}
\mathrm{e}+\mathrm{O}_{2} \rightarrow \mathrm{O}+\mathrm{O}\left({ }^{1} \mathrm{D}\right)+\mathrm{e}, \\
\mathrm{He}+\mathrm{O}\left({ }^{1} \mathrm{D}\right) \rightarrow \mathrm{He}+\mathrm{O}, \\
\mathrm{N}_{2}+\mathrm{O}\left({ }^{1} \mathrm{D}\right) \rightarrow \mathrm{N}_{2}+\mathrm{O}, \\
\mathrm{N}_{2}(\mathrm{~A})+\mathrm{O}_{2} \rightarrow \mathrm{N}_{2}+2 \mathrm{O} .
\end{gathered}
$$

Other ROS including $\mathrm{OH}, \mathrm{HO}_{2}, \mathrm{H}_{2} \mathrm{O}_{2}$, and $\mathrm{O}_{3}$ are not directly produced by electron impact reactions. Instead, $\mathrm{O}, \mathrm{O}\left({ }^{1} \mathrm{D}\right), \mathrm{O}^{-}$, and/or $\mathrm{O}_{2}{ }^{-}$are the precursors of them. Taking $\mathrm{OH}$ as an example, the reaction between $\mathrm{O}$ and $\mathrm{HO}_{2}$ (R104) always plays a dominant role for its production, contributing more than $46 \%$ of its total production rate. This reaction also contributes $16 \%-26 \%$ of the total destruction of $\mathrm{O}$ with varied air concentration. In addition, the charge transfer reaction between $\mathrm{O}^{-}$and $\mathrm{H}_{2} \mathrm{O}$ (R39), the collisional quenching of $\mathrm{O}\left({ }^{1} \mathrm{D}\right)$ by $\mathrm{H}_{2} \mathrm{O}$ (R76), and the reaction between $\mathrm{O}_{3}$ and $\mathrm{H}$ (R105) are also important for $\mathrm{OH}$ production. The main reactions for $\mathrm{OH}$ production are listed below:

$$
\begin{gathered}
\mathrm{O}+\mathrm{HO}_{2} \rightarrow \mathrm{OH}+\mathrm{O}_{2}, \\
\mathrm{O}^{-}+\mathrm{H}_{2} \mathrm{O} \rightarrow \mathrm{OH}^{-}+\mathrm{OH}, \\
\left.\mathrm{O}^{(1} \mathrm{D}\right)+\mathrm{H}_{2} \mathrm{O} \rightarrow 2 \mathrm{OH}, \\
\mathrm{O}_{3}+\mathrm{H} \rightarrow \mathrm{OH}+\mathrm{O}_{2} .
\end{gathered}
$$

It is interesting that $\mathrm{NO}$ is the precursor for all the other RNS such as $\mathrm{NO}_{2}, \mathrm{NO}_{3}, \mathrm{HNO}_{2}$, and $\mathrm{HNO}_{3}$. Three pathways are most responsible for the generation of $\mathrm{NO}$, as follows:

$$
\begin{gathered}
\mathrm{N}+\mathrm{OH} \rightarrow \mathrm{H}+\mathrm{NO}, \\
\mathrm{N}\left({ }^{2} \mathrm{D}\right)+\mathrm{O}_{2} \rightarrow \mathrm{NO}+\mathrm{O}, \\
\mathrm{N}\left({ }^{2} \mathrm{D}\right)+\mathrm{O}_{2} \rightarrow \mathrm{NO}+\mathrm{O}\left({ }^{1} \mathrm{D}\right) .
\end{gathered}
$$

It should be noted that the chemical pathways of ROS are almost separated from that of the RNS, and R100 is the main chain between those two pathway networks, as illustrated by the yellow dash box and blue dash box as shown in Fig. 11. In addition, some ROS such as O and $\mathrm{OH}$ play an important role in the transformation between different kinds of RNS.

In order to further elucidate the production mechanism of ROS and RNS from an overall perspective, the main production/destruction pathways for the entire ROS and RNS are illustrated in Fig. 12. The red arrows indicate the production pathways, while the blue ones indicate the destruction pathways. The arrow width is proportional to its production or destruction rate, and the percentage value indicates the rate of contribution to the total production/destruction as a function of air concentration from 500 to $10000 \mathrm{ppm}$.

Taking the ROS as a whole, two pathways are mostly responsible for its production, as shown in Fig. 12(a). The first one [Path 1 in Fig. 12(a)] is the electron impact excitation and dissociative excitation of $\mathrm{O}_{2}$, which contributes $72 \%$ to $48 \%$ of the ROS production as a function of air concentration from 500 to $10000 \mathrm{ppm}$. This pathway contains the reaction $\mathrm{R} 7$ and $\mathrm{R} 8$ as follows:

$$
\begin{gathered}
\mathrm{e}+\mathrm{O}_{2} \rightarrow \mathrm{e}+\mathrm{O}_{2}(\mathrm{a}), \\
\mathrm{e}+\mathrm{O}_{2} \rightarrow \mathrm{O}+\mathrm{O}\left({ }^{1} \mathrm{D}\right)+\mathrm{e} .
\end{gathered}
$$

The second one [Path 2 in Fig. 12(a)] has two steps for generating ROS. It is initiated by the electron impact excitation of $\mathrm{N}_{2}$, and then, the products $\mathrm{N}_{2}(\mathrm{~A})$ and $\mathrm{N}_{2}(\mathrm{~B})$ could react with $\mathrm{O}_{2}$ to produce ROS. This pathway contributes $18 \%$ to $31 \%$ of the ROS production as a function of air concentration, and the reactions are as follows:

$$
\begin{aligned}
& \mathrm{e}+\mathrm{N}_{2} \rightarrow \mathrm{N}_{2}(\mathrm{~A})+\mathrm{e}, \\
& \mathrm{e}+\mathrm{N}_{2} \rightarrow \mathrm{N}_{2}(\mathrm{~B})+\mathrm{e},
\end{aligned}
$$




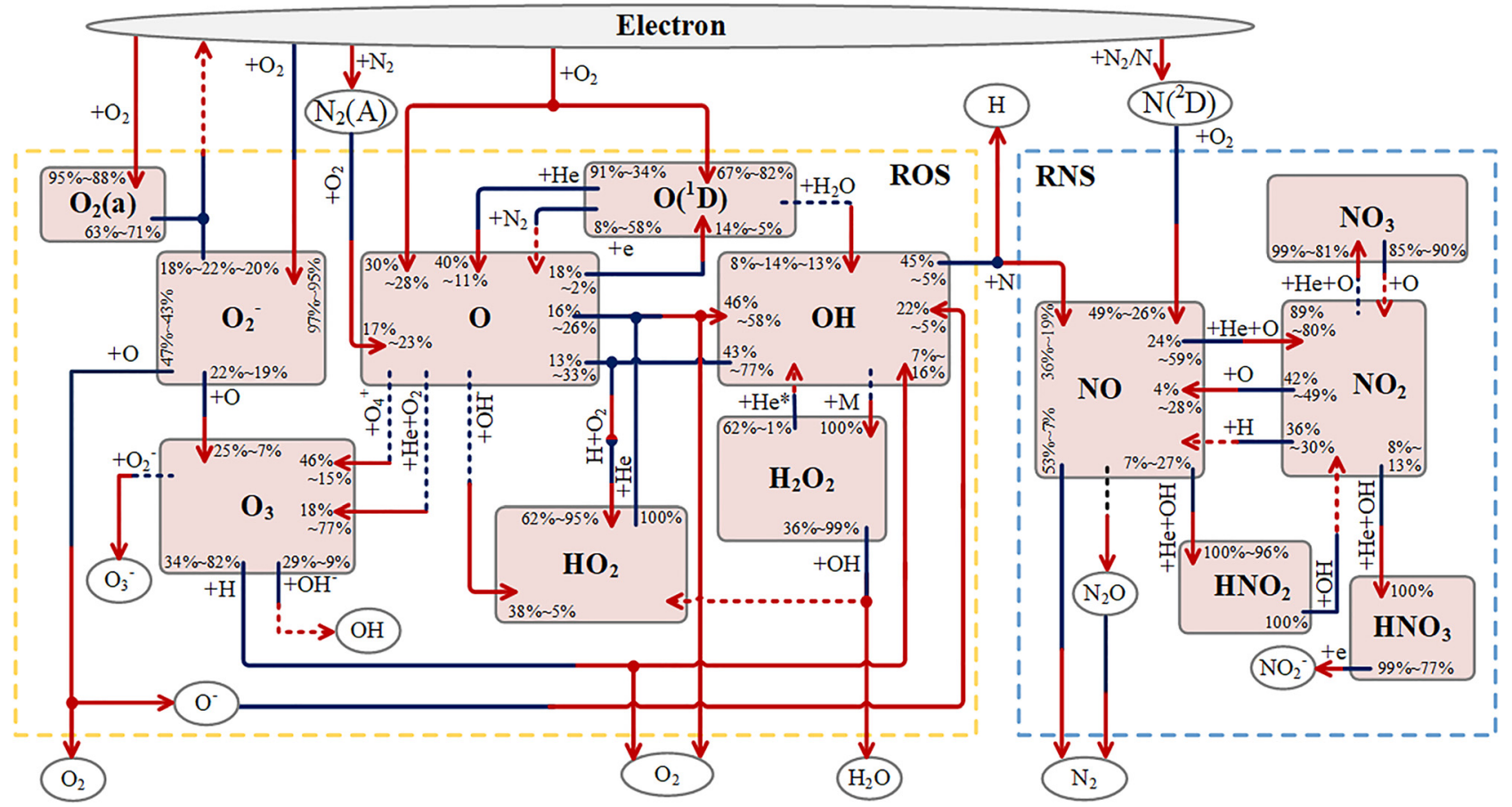

FIG. 11. Main chemical pathways for the generation/loss of the selected biologically active species in He+Air CAPs. Solid lines represent important pathways while dotted lines represent unimportant pathways; blue lines represent destruction while red lines represent production. Percentage ranges in each red box represent the portion of rate of the corresponding reaction to the whole generation/loss rate of the specific species with the air concentration ranging from 500 to $10000 \mathrm{ppm}$.

$$
\begin{aligned}
& \mathrm{N}_{2}(\mathrm{~A})+\mathrm{O}_{2} \rightarrow \mathrm{N}_{2}+2 \mathrm{O}, \\
& \mathrm{N}_{2}(\mathrm{~B})+\mathrm{O}_{2} \rightarrow \mathrm{N}_{2}+2 \mathrm{O} .
\end{aligned}
$$

For the destruction of ROS as a whole, it is mainly transformed back to $\mathrm{O}_{2}$, while a part of it is also transformed to NO. There are four main pathways: (1) the neutral reaction between $\mathrm{O}$ and $\mathrm{OH}$ (Path 3, R103) which contributes $30 \%-80 \%$ of the destruction; (2) the charge transfer reactions (Path $4, \mathrm{R} 42$, and $\mathrm{R} 43$ ) which contribute $25 \%-6 \%$ of the destruction; (3) the collisional detachment of $\mathrm{O}_{2}{ }^{-}$(Path 5, R55, and

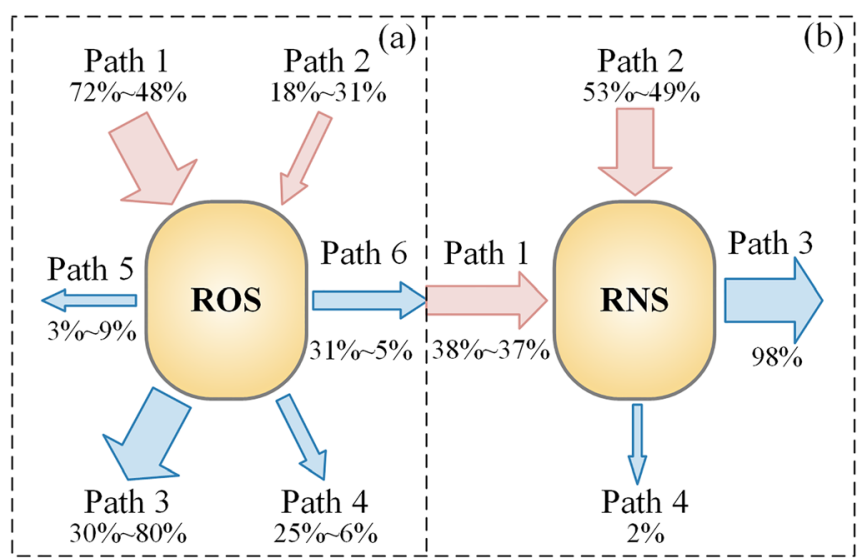

FIG. 12. Main chemical pathways for the production and destruction of the entire (a) ROS and (b) RNS.
R57) which contributes 3\%-9\% of the destruction and (4) the neutral reaction between $\mathrm{N}$ and $\mathrm{OH}$ to form $\mathrm{NO}$ (Path 6, R100) which contributes $31 \%-5 \%$ of the destruction. All the reactions are listed below:

$$
\begin{gathered}
\mathrm{O}+\mathrm{OH} \rightarrow \mathrm{H}+\mathrm{O}_{2}, \\
\mathrm{O}_{2}{ }^{-}+\mathrm{O} \rightarrow \mathrm{O}^{-}+\mathrm{O}_{2}, \\
\mathrm{O}_{2}{ }^{-}+\mathrm{O}_{3} \rightarrow \mathrm{O}_{3}{ }^{-}+\mathrm{O}_{2}, \\
\mathrm{O}_{2}{ }^{-}+\mathrm{O}_{3} \rightarrow \mathrm{O}_{3}+\mathrm{O}_{2}+\mathrm{e}, \\
\mathrm{O}_{2}{ }^{-}+\mathrm{O}_{2}(\mathrm{a}) \rightarrow 2 \mathrm{O}_{2}+\mathrm{e}, \\
\mathrm{N}+\mathrm{OH} \rightarrow \mathrm{H}+\mathrm{NO} .
\end{gathered}
$$

Taking the RNS as a whole, there are also two main pathways contribute to its production, as shown in Fig. 12(b). The first one is the neutral reaction between $\mathrm{OH}$ and $\mathrm{N}$ to form $\mathrm{NO}$ (R100), which is Path 1 in Fig. 12(b) and also Path 6 in Fig. 12(a). It is the main chain between the ROS and RNS, which contributes on $31 \%-5 \%$ of the ROS destruction while $38 \%-37 \%$ of the RNS production. The second one (Path 2, R5, R79, and R80) has two steps: it is initiated by the electron impact dissociative excitation of $\mathrm{N}_{2}$, and then the product $\mathrm{N}\left({ }^{2} \mathrm{D}\right)$ could react with $\mathrm{O}_{2}$ to produce NO. This pathway contributes $53 \%$ to $49 \%$ of the RNS production as a function of air concentration, and the reactions are as follows:

$$
\begin{gathered}
\left.\mathrm{e}+\mathrm{N}_{2} \rightarrow \mathrm{N}^{(2} \mathrm{D}\right)+\mathrm{N}+\mathrm{e} \\
\mathrm{N}\left({ }^{2} \mathrm{D}\right)+\mathrm{O}_{2} \rightarrow \mathrm{NO}+\mathrm{O}, \\
\mathrm{N}\left({ }^{2} \mathrm{D}\right)+\mathrm{O}_{2} \rightarrow \mathrm{NO}+\mathrm{O}\left({ }^{1} \mathrm{D}\right)
\end{gathered}
$$


For the destruction of RNS as a whole, it is mainly transformed back to $\mathrm{N}_{2}$. There are two main destruction pathways: (1) the neutral reaction from $\mathrm{NO}$ to $\mathrm{N}_{2}$ which contributes $98 \%$ of the destruction (Path 3, R98) and (2) the neutral reaction from $\mathrm{N}_{2} \mathrm{O}$ to $\mathrm{N}_{2}$ which contributes just $2 \%$ of the destruction (Path 4, R86, and R87). The destruction reactions are as follows:

$$
\begin{gathered}
\mathrm{N}+\mathrm{NO} \rightarrow \mathrm{N}_{2}+\mathrm{O}, \\
\mathrm{N}_{2}(\mathrm{~A})+\mathrm{N}_{2} \mathrm{O} \rightarrow \mathrm{O}+2 \mathrm{~N}_{2}, \\
\mathrm{~N}_{2}(\mathrm{~A})+\mathrm{N}_{2} \mathrm{O} \rightarrow \mathrm{NO}+\mathrm{N}+\mathrm{N}_{2} .
\end{gathered}
$$

\section{CONCLUSIONS}

In summation, a $1 \mathrm{D}$ fluid model of cold atmospheric $\mathrm{He}+\mathrm{Air}$ CAPs, which incorporates 48 species and 118 reactions has been developed, with which the density distribution of reactive species, the power dissipation characteristics and the chemistry pathways among the reactive species are studied as a function of air concentration from 500 to $10000 \mathrm{ppm}$. It is found that the electron density decreases from $1.5 \times 10^{11}$ to $4.4 \times 10^{10} \mathrm{~cm}^{-3}$ and consequently, the electron-coupled power reduces. However, more input power is dissipated on the inelastic collisions between the electrons and air gases, leading to an increasing production of reactive oxygen species (ROS) and reactive nitrogen species (RNS). O and NO are the dominant ROS and RNS, respectively. Taking the ROS as a whole, it is mainly produced by the electron impact dissociation and excitation of $\mathrm{O}_{2}$, while the electron impact excitation of $\mathrm{N}_{2}$ has a non-negligible contribution of more than $10 \%$; taking the RNS as a whole, it is mainly produced by the oxidation of atomic nitrogen $\left[\mathrm{N}\right.$ and $\left.\mathrm{N}\left({ }^{2} \mathrm{D}\right)\right]$, and $\mathrm{NO}$ is the precursor for all the other RNS. The main chemical pathways of ROS are almost separated from that of the RNS, and the main chain connecting the two chemical networks is the oxidation of $\mathrm{N}$ by $\mathrm{OH}$ to form $\mathrm{NO}$ (R100 in the Table II).

\section{ACKNOWLEDGMENTS}

This work was supported by the National Science Foundation of China (Grant Nos. 51722705 and 51837008), the Fok Ying-Tong Education Foundation (No. 161055), the State Key Laboratory of Electrical Insulation and Power Equipment (No. EIPE19122), and the Fundamental Research Funds for the Central Universities (No. xzy022019034).

\begin{tabular}{|c|c|c|c|}
\hline No. & Reaction & Rate coefficient ${ }^{\mathrm{a}}$ & References \\
\hline \multicolumn{4}{|c|}{ Electron impact momentum transfer } \\
\hline 1 & $\mathrm{e}+\mathrm{He} \rightarrow \mathrm{e}+\mathrm{He}$ & $f\left(T_{e}\right)$ & $69^{\mathrm{b}}$ \\
\hline \multicolumn{4}{|c|}{ Electron impact excitation and de-excitation } \\
\hline 2 & $\mathrm{e}+\mathrm{N} \rightarrow \mathrm{N}\left({ }^{2} \mathrm{D}\right)+\mathrm{e}$ & $f\left(T_{e}\right)$ & $70^{\mathrm{b}}$ \\
\hline 3 & $\mathrm{e}+\mathrm{N}_{2} \rightarrow \mathrm{N}_{2}(\mathrm{~A})+\mathrm{e}$ & $f\left(T_{e}\right)$ & $71^{\mathrm{b}}$ \\
\hline 4 & $\mathrm{e}+\mathrm{N}_{2} \rightarrow \mathrm{N}_{2}(\mathrm{~B})+\mathrm{e}$ & $f\left(T_{e}\right)$ & $71^{\mathrm{b}}$ \\
\hline 5 & $\mathrm{e}+\mathrm{N}_{2} \rightarrow \mathrm{N}\left({ }^{2} \mathrm{D}\right)+\mathrm{N}+\mathrm{e}$ & $f\left(T_{e}\right)$ & $72^{\mathrm{b}}$ \\
\hline 6 & $\mathrm{e}+\mathrm{O} \rightarrow \mathrm{e}+\mathrm{O}\left({ }^{1} \mathrm{D}\right)$ & $f\left(T_{e}\right)$ & $73^{\mathrm{b}}$ \\
\hline 7 & $\mathrm{e}+\mathrm{O}_{2} \rightarrow \mathrm{e}+\mathrm{O}_{2}(\mathrm{a})$ & $f\left(T_{e}\right)$ & $74^{\mathrm{b}}$ \\
\hline 8 & $\mathrm{e}+\mathrm{O}_{2} \rightarrow \mathrm{O}\left({ }^{1} \mathrm{D}\right)+\mathrm{O}+\mathrm{e}$ & $f\left(T_{e}\right)$ & $75^{\mathrm{b}}$ \\
\hline 9 & $\mathrm{e}+\mathrm{H}_{2} \mathrm{O} \rightarrow \mathrm{H}_{2}+\mathrm{O}\left({ }^{1} \mathrm{D}\right)+\mathrm{e}$ & $f\left(T_{e}\right)$ & $76^{\mathrm{b}}$ \\
\hline 10 & $\mathrm{e}+\mathrm{He} \rightarrow \mathrm{e}+\mathrm{He}^{*}$ & $f\left(T_{e}\right)$ & $69^{\mathrm{b}}$ \\
\hline 11 & $\mathrm{e}+\mathrm{H}_{2} \mathrm{O} \rightarrow \mathrm{H}+\mathrm{OH}(\mathrm{A})+\mathrm{e}$ & $f\left(T_{e}\right)$ & $77^{\mathrm{b}}$ \\
\hline 12 & $\mathrm{e}+\mathrm{OH} \rightarrow \mathrm{OH}(\mathrm{A})+\mathrm{e}$ & $f\left(T_{e}\right)$ & $69,78^{c}$ \\
\hline \multicolumn{4}{|c|}{ Electron impact dissociation } \\
\hline 13 & $\mathrm{e}+\mathrm{H}_{2} \mathrm{O} \rightarrow \mathrm{OH}+\mathrm{H}+\mathrm{e}$ & $f\left(T_{e}\right)$ & $77^{\mathrm{b}}$ \\
\hline 14 & $\mathrm{e}+\mathrm{O}_{3} \rightarrow \mathrm{O}+\mathrm{O}_{2}+\mathrm{e}$ & $f\left(T_{e}\right)$ & $79^{\mathrm{b}}$ \\
\hline \multicolumn{4}{|c|}{ Electron impact attachment and dissociative attachment } \\
\hline 15 & $\mathrm{e}+\mathrm{O}_{2} \rightarrow \mathrm{O}_{2}^{-}$ & $f\left(T_{e}\right)$ & $80^{\mathrm{b}}$ \\
\hline 16 & $\mathrm{e}+\mathrm{O}_{2} \rightarrow \mathrm{O}^{-}+\mathrm{O}$ & $f\left(T_{e}\right)$ & $81^{\mathrm{b}}$ \\
\hline 17 & $\mathrm{e}+\mathrm{O}_{3} \rightarrow \mathrm{O}+\mathrm{O}_{2}^{-}$ & $f\left(T_{e}\right)$ & $81^{\mathrm{b}}$ \\
\hline 18 & $\mathrm{e}+\mathrm{O}_{3} \rightarrow \mathrm{O}^{-}+\mathrm{O}_{2}$ & $f\left(T_{e}\right)$ & $81^{\mathrm{b}}$ \\
\hline 19 & $\mathrm{e}+\mathrm{H}_{2} \mathrm{O} \rightarrow \mathrm{H}^{-}+\mathrm{OH}$ & $f\left(T_{e}\right)$ & $81^{\mathrm{b}}$ \\
\hline
\end{tabular}

\section{APPENDIX}

TABLE II. Chemical reactions included in He+Air plasmas. Note: $\mathrm{T}_{\mathrm{e}}$ in $\mathrm{eV} ; \mathrm{T}_{\mathrm{g}}$ in Kelvin, which is $360 \mathrm{~K}$ here; $\mathrm{M}$ represents the feeding gas. 
TABLE II. (Continued.)

\begin{tabular}{|c|c|c|c|}
\hline No. & Reaction & Rate coefficient ${ }^{\mathrm{a}}$ & References \\
\hline 20 & $\mathrm{e}+\mathrm{HNO}_{3} \rightarrow \mathrm{NO}_{2}^{-}+\mathrm{OH}$ & $5 \times 10^{-8}$ & 82 \\
\hline 21 & $\mathrm{e}+\mathrm{NO}+\mathrm{He} \rightarrow \mathrm{NO}^{-}+\mathrm{He}$ & $8 \times 10^{-31}$ & 83 \\
\hline \multicolumn{4}{|c|}{ Ion-ion recombination } \\
\hline 22 & $\mathrm{NO}^{+}+\mathrm{NO}_{3}^{-} \rightarrow \mathrm{NO}_{3}+\mathrm{NO}$ & $2 \times 10^{-7} \times\left(300 / T_{g}\right)^{0.5}$ & 84 \\
\hline 23 & $\mathrm{NO}_{2}^{+}+\mathrm{NO}_{3}^{-} \rightarrow \mathrm{NO}_{3}+\mathrm{NO}_{2}$ & $2 \times 10^{-7} \times\left(300 / T_{g}\right)^{0.5}$ & 82 \\
\hline \multicolumn{4}{|c|}{ Charge transfer } \\
\hline 24 & $\mathrm{~N}_{2}^{+}+\mathrm{H}_{2} \mathrm{O} \rightarrow \mathrm{H}_{2} \mathrm{O}^{+}+\mathrm{N}_{2}$ & $2.3 \times 10^{-9}$ & 83 \\
\hline 25 & $\mathrm{~N}_{3}^{+}+\mathrm{O}_{2} \rightarrow \mathrm{O}_{2}^{+}+\mathrm{N}+\mathrm{N}_{2}$ & $2.3 \times 10^{-11}$ & 83 \\
\hline 26 & $\mathrm{~N}_{3}^{+}+\mathrm{O}_{2} \rightarrow \mathrm{NO}^{+}+\mathrm{O}+\mathrm{N}_{2}$ & $2 \times 10^{-11}$ & 83 \\
\hline 27 & $\mathrm{~N}_{3}^{+}+\mathrm{O}_{2} \rightarrow \mathrm{NO}_{2}^{+}+\mathrm{N}_{2}$ & $4.4 \times 10^{-11}$ & 83 \\
\hline 28 & $\mathrm{~N}_{4}^{+}+\mathrm{N}_{2} \rightarrow \mathrm{N}_{2}^{+}+2 \mathrm{~N}_{2}$ & $2.1 \times 10^{-10} \times \exp \left(T_{g} / 121\right)$ & 83 \\
\hline 29 & $\mathrm{~N}_{4}^{+}+\mathrm{H}_{2} \mathrm{O} \rightarrow \mathrm{H}_{2} \mathrm{O}^{+}+2 \mathrm{~N}_{2}$ & $3 \times 10^{-9}$ & 83 \\
\hline 30 & $\mathrm{O}_{2}{ }^{+}+\mathrm{N}_{2} \mathrm{O}_{5} \rightarrow \mathrm{NO}_{2}{ }^{+}+\mathrm{NO}_{3}+\mathrm{O}_{2}$ & $8.8 \times 10^{-10}$ & 84 \\
\hline 31 & $\mathrm{O}_{4}^{+}+\mathrm{O} \rightarrow \mathrm{O}_{2}^{+}+\mathrm{O}_{3}$ & $3 \times 10^{-10}$ & 83 \\
\hline 32 & $\mathrm{O}_{4}^{+}+\mathrm{NO} \rightarrow \mathrm{NO}^{+}+2 \mathrm{O}_{2}$ & $6.8 \times 10^{-10}$ & 85 \\
\hline 33 & $\mathrm{NO}^{+}+\mathrm{N}_{2} \mathrm{O}_{5} \rightarrow \mathrm{NO}_{2}^{+}+2 \mathrm{NO}_{2}$ & $5.9 \times 10^{-10}$ & 84 \\
\hline 34 & $\mathrm{NO}_{2}^{+}+\mathrm{NO} \rightarrow \mathrm{NO}^{+}+\mathrm{NO}_{2}$ & $2.75 \times 10^{-10}$ & 86 \\
\hline 35 & $\mathrm{OH}^{+}+\mathrm{O}_{2} \rightarrow \mathrm{O}_{2}^{+}+\mathrm{OH}$ & $5.9 \times 10^{-10}$ & 85 \\
\hline 36 & $\mathrm{H}_{2} \mathrm{O}^{+}+\mathrm{O}_{2} \rightarrow \mathrm{O}_{2}^{+}+\mathrm{H}_{2} \mathrm{O}$ & $4.3 \times 10^{-10}$ & 83 \\
\hline 37 & $\mathrm{H}_{2} \mathrm{O}^{+}+\mathrm{H}_{2} \mathrm{O} \rightarrow \mathrm{H}_{3} \mathrm{O}^{+}+\mathrm{OH}$ & $1.7 \times 10^{-9}$ & 83 \\
\hline 38 & $\mathrm{H}_{3} \mathrm{O}^{+}+\mathrm{N}_{2} \mathrm{O}_{5} \rightarrow \mathrm{NO}_{2}^{+}+\mathrm{HNO}_{3}+\mathrm{H}_{2} \mathrm{O}$ & $5.5 \times 10^{-10}$ & 82 \\
\hline 39 & $\mathrm{O}^{-}+\mathrm{H}_{2} \mathrm{O} \rightarrow \mathrm{OH}^{-}+\mathrm{OH}$ & $1.4 \times 10^{-9}$ & 83 \\
\hline 40 & $\mathrm{O}^{-}+\mathrm{O}_{2}(\mathrm{a}) \rightarrow \mathrm{O}_{2}^{-}+\mathrm{O}$ & $1 \times 10^{-10}$ & 83 \\
\hline 41 & $\mathrm{O}^{-}+\mathrm{O}_{3} \rightarrow \mathrm{O}_{3}^{-}+\mathrm{O}$ & $8 \times 10^{-10}$ & 83 \\
\hline 42 & $\mathrm{O}_{2}^{-}+\mathrm{O} \rightarrow \mathrm{O}^{-}+\mathrm{O}_{2}$ & $3.3 \times 10^{-10}$ & 83 \\
\hline 43 & $\mathrm{O}_{2}^{-}+\mathrm{O}_{3} \rightarrow \mathrm{O}_{3}^{-}+\mathrm{O}_{2}$ & $3.5 \times 10^{-10}$ & 83 \\
\hline 44 & $\mathrm{NO}^{-}+\mathrm{O}_{2} \rightarrow \mathrm{O}_{2}^{-}+\mathrm{NO}$ & $5 \times 10^{-10}$ & 83 \\
\hline 45 & $\mathrm{NO}_{2}^{-}+\mathrm{N}_{2} \mathrm{O}_{5} \rightarrow \mathrm{NO}_{3}^{-}+\mathrm{NO}_{3}+\mathrm{NO}$ & $7 \times 10^{-10}$ & 83 \\
\hline 46 & $\mathrm{NO}_{2}^{-}+\mathrm{NO} \rightarrow \mathrm{NO}^{-}+\mathrm{NO}_{2}$ & $2.75 \times 10^{-10}$ & 86 \\
\hline 47 & $\mathrm{NO}_{2}{ }^{-}+\mathrm{HNO}_{3} \rightarrow \mathrm{NO}_{3}^{-}+\mathrm{HNO}_{2}$ & $1.6 \times 10^{-9}$ & 87 \\
\hline 48 & $\mathrm{OH}^{-}+\mathrm{O}_{3} \rightarrow \mathrm{O}_{3}^{-}+\mathrm{OH}$ & $9 \times 10^{-10}$ & 88 \\
\hline 49 & $\mathrm{He}+\mathrm{O}^{-}+\mathrm{O}_{2} \rightarrow \mathrm{He}+\mathrm{O}_{3}^{-}$ & $1.1 \times 10^{-30} \times\left(T_{g} / 300\right)^{-1}$ & 89 \\
\hline 50 & $\mathrm{He}+\mathrm{O}^{+}+\mathrm{N}_{2} \rightarrow \mathrm{He}+\mathrm{NO}^{+}+\mathrm{N}$ & $6 \times 10^{-29} \times\left(T_{g} / 300\right)^{-2}$ & 89 \\
\hline 51 & $\mathrm{He}+\mathrm{O}_{2}^{+}+\mathrm{O}_{2} \rightarrow \mathrm{He}+\mathrm{O}_{4}^{+}$ & $3.9 \times 10^{-30} \times\left(T_{g} / 300\right)^{-3.2}$ & 89 \\
\hline 52 & $\mathrm{He}+\mathrm{N}_{2}^{+}+\mathrm{N}_{2} \rightarrow \mathrm{He}+\mathrm{N}_{4}^{+}$ & $5 \times 10^{-29} \times\left(T_{g} / 300\right)^{-1}$ & 89 \\
\hline 53 & $\mathrm{He}+\mathrm{N}^{+}+\mathrm{N}_{2} \rightarrow \mathrm{He}+\mathrm{N}_{3}^{+}$ & $4.6 \times 10^{-29}$ & 90 \\
\hline \multicolumn{4}{|c|}{ Collisional detachment } \\
\hline 54 & $\mathrm{O}^{-}+\mathrm{O}_{2}(\mathrm{a}) \rightarrow \mathrm{O}_{3}+\mathrm{e}$ & $3 \times 10^{-10}$ & 83 \\
\hline 55 & $\mathrm{O}_{2}^{-}+\mathrm{O}_{3} \rightarrow \mathrm{O}_{2}+\mathrm{O}_{3}+\mathrm{e}$ & $6 \times 10^{-10}$ & 91 \\
\hline 56 & $\mathrm{O}_{2}^{-}+\mathrm{O} \rightarrow \mathrm{O}_{3}+\mathrm{e}$ & $1.5 \times 10^{-10}$ & 83 \\
\hline 57 & $\mathrm{O}_{2}^{-}+\mathrm{O}_{2}(\mathrm{a}) \rightarrow 2 \mathrm{O}_{2}+\mathrm{e}$ & $2 \times 10^{-10}$ & 83 \\
\hline 58 & $\mathrm{OH}^{-}+\mathrm{O} \rightarrow \mathrm{HO}_{2}+\mathrm{e}$ & $2 \times 10^{-10}$ & 88 \\
\hline 59 & $\mathrm{He}+\mathrm{O}_{3}{ }^{-} \rightarrow \mathrm{He}+\mathrm{O}+\mathrm{O}_{2}+\mathrm{e}$ & $3 \times 10^{-10}$ & 92 \\
\hline 60 & $\mathrm{He}+\mathrm{H}^{-} \rightarrow \mathrm{He}+\mathrm{H}+\mathrm{e}$ & $8 \times 10^{-18}\left(T_{g} / 300\right)^{0.5}$ & 93 \\
\hline 61 & $\mathrm{He}+\mathrm{NO}^{-} \rightarrow \mathrm{He}+\mathrm{NO}+\mathrm{e}$ & $2.4 \times 10^{-13}$ & 94 \\
\hline \multicolumn{4}{|c|}{ Penning ionization } \\
\hline 62 & $\mathrm{He}^{*}+\mathrm{O} \rightarrow \mathrm{O}^{+}+\mathrm{He}+\mathrm{e}$ & $3.96 \times 10^{-10}\left(T_{g} / 300\right)^{0.17}$ & 95 \\
\hline
\end{tabular}


TABLE II. (Continued.)

\begin{tabular}{|c|c|c|c|}
\hline No. & Reaction & Rate coefficient ${ }^{a}$ & References \\
\hline 63 & $\mathrm{He}^{*}+\mathrm{O}_{2} \rightarrow \mathrm{O}_{2}^{+}+\mathrm{He}+\mathrm{e}$ & $2.54 \times 10^{-10}\left(T_{g} / 300\right)^{0.5}$ & 96 \\
\hline 64 & $\mathrm{He}^{*}+\mathrm{H}_{2} \mathrm{O} \rightarrow \mathrm{He}+\mathrm{OH}^{+}+\mathrm{H}+\mathrm{e}$ & $1.5 \times 10^{-10}$ & 97 \\
\hline 65 & $\mathrm{He}^{*}+\mathrm{H}_{2} \mathrm{O}_{2} \rightarrow \mathrm{He}+\mathrm{OH}^{+}+\mathrm{OH}+\mathrm{e}$ & $7.8 \times 10^{-10}$ & 69 \\
\hline 66 & $\mathrm{He}^{*}+\mathrm{N}_{2} \rightarrow \mathrm{He}+\mathrm{N}_{2}^{+}+\mathrm{e}$ & $5 \times 10^{-11}$ & 98 \\
\hline 67 & $\mathrm{He}^{*}+\mathrm{N}_{2} \rightarrow \mathrm{He}+\mathrm{N}^{+}+\mathrm{N}+\mathrm{e}$ & $1 \times 10^{-10}$ & 92 \\
\hline 68 & $\mathrm{He}_{2}{ }^{*}+\mathrm{O} \rightarrow 2 \mathrm{He}+\mathrm{O}^{+}+\mathrm{e}$ & $3.6 \times 10^{-10}$ & 99 \\
\hline 69 & $\mathrm{He}_{2}{ }^{*}+\mathrm{O}_{2} \rightarrow 2 \mathrm{He}+\mathrm{O}_{2}^{+}+\mathrm{e}$ & $3.6 \times 10^{-10}$ & 99 \\
\hline 70 & $\mathrm{He}_{2}{ }^{*}+\mathrm{H}_{2} \mathrm{O}_{2} \rightarrow 2 \mathrm{He}+\mathrm{OH}^{+}+\mathrm{OH}+\mathrm{e}$ & $6 \times 10^{-10}$ & 69 \\
\hline 71 & $\mathrm{He}_{2}^{*}+\mathrm{N}_{2} \rightarrow 2 \mathrm{He}+\mathrm{N}_{2}^{+}+\mathrm{e}$ & $3 \times 10^{-11}$ & 100 \\
\hline \multicolumn{4}{|c|}{ Radiation } \\
\hline 72 & $\mathrm{~N}_{2}(\mathrm{~B}) \rightarrow \mathrm{N}_{2}(\mathrm{~A})$ & $1.25 \times 10^{5}$ & 101 \\
\hline \multicolumn{4}{|c|}{ Other neutral reactions } \\
\hline 73 & $\mathrm{O}\left({ }^{1} \mathrm{D}\right)+\mathrm{He} \rightarrow \mathrm{O}+\mathrm{He}$ & $1.0 \times 10^{-13}$ & 96 \\
\hline 74 & $\mathrm{O}\left({ }^{1} \mathrm{D}\right)+\mathrm{N}_{2} \rightarrow \mathrm{O}+\mathrm{N}_{2}$ & $1.8 \times 10^{-11} \times \exp \left(107 / T_{g}\right)$ & 102 \\
\hline 75 & $\mathrm{O}\left({ }^{1} \mathrm{D}\right)+\mathrm{H}_{2} \rightarrow \mathrm{OH}+\mathrm{H}$ & $1.1 \times 10^{-10}$ & 103 \\
\hline 76 & $\mathrm{O}\left({ }^{1} \mathrm{D}\right)+\mathrm{H}_{2} \mathrm{O} \rightarrow \mathrm{OH}+\mathrm{OH}$ & $2.2 \times 10^{-10}$ & 104 \\
\hline 77 & $\mathrm{O}_{2}(\mathrm{a})+\mathrm{O}_{3} \rightarrow \mathrm{O}+2 \mathrm{O}_{2}$ & $5.2 \times 10^{-11} \times \exp \left(-2840 / T_{g}\right)$ & 102 \\
\hline 78 & $\mathrm{~N}\left({ }^{2} \mathrm{D}\right)+\mathrm{NO} \rightarrow \mathrm{N}_{2} \mathrm{O}$ & $6 \times 10^{-11}$ & 84 \\
\hline 79 & $\mathrm{~N}\left({ }^{2} \mathrm{D}\right)+\mathrm{O}_{2} \rightarrow \mathrm{NO}+\mathrm{O}$ & $1.5 \times 10^{-12} \times\left(T_{g} / 300\right)^{0.5}$ & 84 \\
\hline 80 & $\mathrm{~N}\left({ }^{2} \mathrm{D}\right)+\mathrm{O}_{2} \rightarrow \mathrm{NO}+\mathrm{O}\left({ }^{1} \mathrm{D}\right)$ & $6 \times 10^{-12} \times\left(T_{g}^{\delta} / 300\right)^{0.5}$ & 84 \\
\hline 81 & $\mathrm{~N}_{2}(\mathrm{~A})+\mathrm{O} \rightarrow \mathrm{O}\left({ }^{1} \mathrm{D}\right)+\mathrm{N}_{2}$ & $2.3 \times 10^{-11}$ & 82 \\
\hline 82 & $\mathrm{~N}_{2}(\mathrm{~A})+\mathrm{O} \rightarrow \mathrm{NO}+\mathrm{N}\left({ }^{2} \mathrm{D}\right)$ & $7 \times 10^{-12}$ & 83 \\
\hline 83 & $\mathrm{~N}_{2}(\mathrm{~A})+\mathrm{O}_{2} \rightarrow \mathrm{O}_{2}(\mathrm{a})+\mathrm{N}_{2}$ & $1 \times 10^{-12}$ & 82 \\
\hline 84 & $\mathrm{~N}_{2}(\mathrm{~A})+\mathrm{O}_{2} \rightarrow \mathrm{N}_{2}+2 \mathrm{O}$ & $5 \times 10^{-12} \times \exp \left(-210 / T_{g}\right)$ & 102 \\
\hline 85 & $\mathrm{~N}_{2}(\mathrm{~A})+\mathrm{N}_{2}(\mathrm{~A}) \rightarrow \mathrm{N}_{2}(\mathrm{~B})+\mathrm{N}_{2}$ & $4 \times 10^{-10}$ & 102 \\
\hline 86 & $\mathrm{~N}_{2}(\mathrm{~A})+\mathrm{N}_{2} \mathrm{O} \rightarrow \mathrm{O}+2 \mathrm{~N}_{2}$ & $8 \times 10^{-11}$ & 82 \\
\hline 87 & $\mathrm{~N}_{2}(\mathrm{~A})+\mathrm{N}_{2} \mathrm{O} \rightarrow \mathrm{NO}+\mathrm{N}+\mathrm{N}_{2}$ & $8 \times 10^{-11}$ & 82 \\
\hline 88 & $\mathrm{~N}_{2}(\mathrm{~B})+\mathrm{O}_{2} \rightarrow \mathrm{N}_{2}+2 \mathrm{O}$ & $3 \times 10^{-10}$ & 83 \\
\hline 89 & $\mathrm{~N}_{2}(\mathrm{~B})+\mathrm{N}_{2} \rightarrow \mathrm{N}_{2}(\mathrm{~A})+\mathrm{N}_{2}$ & $5 \times 10^{-11}$ & 84 \\
\hline 90 & $\mathrm{~N}_{2}(\mathrm{~B})+\mathrm{He} \rightarrow \mathrm{N}_{2}+\mathrm{He}$ & $1 \times 10^{-12}$ & 105 \\
\hline 91 & $\mathrm{OH}(\mathrm{A})+\mathrm{He} \rightarrow \mathrm{He}+\mathrm{OH}$ & $1.5 \times 10^{-14}$ & 106 \\
\hline 92 & $\mathrm{OH}(\mathrm{A})+\mathrm{O} \rightarrow \mathrm{H}+\mathrm{O}_{2}$ & $4.3 \times 10^{-11} \times\left(T_{g} / 300\right)^{-0.5}$ & 107 \\
\hline 93 & $\mathrm{OH}(\mathrm{A})+\mathrm{O}_{2} \rightarrow \mathrm{OH}+\mathrm{O}_{2}$ & $7.5 \times 10^{-11} \times\left(T_{g} / 300\right)^{-0.5}$ & 108 \\
\hline 94 & $\mathrm{OH}(\mathrm{A})+\mathrm{N}_{2} \rightarrow \mathrm{N}_{2}+\mathrm{OH}$ & $3.1 \times 10^{-11}$ & 108 \\
\hline 95 & $\mathrm{OH}(\mathrm{A})+\mathrm{H}_{2} \mathrm{O} \rightarrow \mathrm{H}_{2} \mathrm{O}+\mathrm{OH}$ & $4.9 \times 10^{-10} \times\left(T_{g} / 300\right)^{-0.5}$ & 108 \\
\hline 96 & $\mathrm{He}^{*}+2 \mathrm{He} \rightarrow \mathrm{He}_{2}^{*}+\mathrm{He}$ & $1.5 \times 10^{-34}$ & 99 \\
\hline 97 & $\mathrm{M}+\mathrm{O}_{3} \rightarrow \mathrm{M}+\mathrm{O}+\mathrm{O}_{2}$ & $1.56 \times 10^{-9} \times \exp \left(11400 / T_{g}\right)$ & 96,99 \\
\hline 98 & $\mathrm{~N}+\mathrm{NO} \rightarrow \mathrm{N}_{2}+\mathrm{O}$ & $2.1 \times 10^{-11} \times \exp \left(100 / T_{g}\right)$ & 102 \\
\hline 99 & $\mathrm{~N}+\mathrm{NO}_{2} \rightarrow \mathrm{N}_{2} \mathrm{O}+\mathrm{O}$ & $5.8 \times 10^{-12} \times \exp \left(220 / T_{g}\right)$ & 102 \\
\hline 100 & $\mathrm{~N}+\mathrm{OH} \rightarrow \mathrm{H}+\mathrm{NO}$ & $7.5 \times 10^{-11}$ & 83 \\
\hline 101 & $\mathrm{O}+\mathrm{NO}_{2} \rightarrow \mathrm{NO}+\mathrm{O}_{2}$ & $6.5 \times 10^{-12} \times \exp \left(120 / T_{g}\right)$ & 102 \\
\hline 102 & $\mathrm{O}+\mathrm{NO}_{3} \rightarrow \mathrm{NO}_{2}+\mathrm{O}_{2}$ & $1.7 \times 10^{-11}$ & 102 \\
\hline 103 & $\mathrm{O}+\mathrm{OH} \rightarrow \mathrm{H}+\mathrm{O}_{2}$ & $2.2 \times 10^{-11} \times \exp \left(-350 / T_{g}\right)$ & 83 \\
\hline 104 & $\mathrm{O}+\mathrm{HO}_{2} \rightarrow \mathrm{OH}+\mathrm{O}_{2}$ & $8.3 \times 10^{-11} \times \exp \left(-500 / T_{g}^{\circ}\right)$ & 83 \\
\hline 105 & $\mathrm{O}_{3}+\mathrm{H} \rightarrow \mathrm{OH}+\mathrm{O}_{2}$ & $2.8 \times 10^{-11} \times\left(T_{g} / 300\right)^{0.75}$ & 83 \\
\hline 106 & $\mathrm{NO}+\mathrm{NO}_{3} \rightarrow 2 \mathrm{NO}_{2}$ & $1.8 \times 10^{-11} \times \exp \left(110 / T_{g}\right)$ & 83 \\
\hline 107 & $\mathrm{NO}_{2}+\mathrm{H} \rightarrow \mathrm{OH}+\mathrm{NO}$ & $1.47 \times 10^{-10}$ & 83 \\
\hline
\end{tabular}


TABLE II. (Continued.)

\begin{tabular}{lccc}
\hline \hline No. & Reaction & Rate coefficient $^{\mathrm{a}}$ & References $^{2}$ \\
\hline 108 & $\mathrm{OH}+\mathrm{H}_{2} \mathrm{O}_{2} \rightarrow \mathrm{HO}_{2}+\mathrm{H}_{2} \mathrm{O}$ & $2.9 \times 10^{-12} \times \exp \left(-160 / T_{g}\right)$ & $1.8 \times 10^{-11} \times \exp \left(-390 / T_{g}\right)$ \\
109 & $\mathrm{OH}+\mathrm{HNO}_{2} \rightarrow \mathrm{NO}_{2}+\mathrm{H}_{2} \mathrm{O}$ & $1.3 \times 10^{-32} \times\left(T_{g} / 300\right)^{-1} \exp \left(-170 / T_{g}\right)$ & 109 \\
110 & $\mathrm{He}+2 \mathrm{O} \rightarrow \mathrm{He}+\mathrm{O}_{2}$ & $3.4 \times 10^{-34} \times\left(T_{g} / 300\right)^{-1.2}$ & 96 \\
111 & $\mathrm{He}+\mathrm{O}+\mathrm{O}_{2} \rightarrow \mathrm{He}+\mathrm{O}_{3}$ & $9 \times 10^{-32}\left(300 / T_{g}\right)^{2}$ & 102 \\
112 & $\mathrm{He}+\mathrm{O}+\mathrm{NO}_{2} \rightarrow \mathrm{He}+\mathrm{NO}_{3}$ & $3.96 \times 10^{-32}\left(T_{g} / 300\right)^{-0.8}\left(T_{g} / 300\right)^{-3.2}$ & 110 \\
113 & $\mathrm{He}+\mathrm{H}+\mathrm{O}_{2} \rightarrow \mathrm{He}+\mathrm{HO}_{2}$ & $1 \times 10^{-31}$ & 110 \\
114 & $\mathrm{He}+2 \mathrm{OH} \rightarrow \mathrm{He}+\mathrm{H}_{2} \mathrm{O}_{2}$ & $2 \times 10^{-31}\left(300 / T_{g}\right)^{2.4}$ & 111 \\
115 & $\mathrm{He}+\mathrm{NO}+\mathrm{O} \rightarrow \mathrm{He}+\mathrm{NO}_{2}$ & $2.2 \times 10^{-30}\left(300 / T_{g}\right)^{2.9}$ & 102 \\
116 & $\mathrm{He}+\mathrm{NO}+\mathrm{OH} \rightarrow \mathrm{He}+\mathrm{HNO}_{2}$ & $2.8 \times 10^{-30}\left(300 / T_{g}\right)^{3.5}$ \\
117 & $\mathrm{He}+\mathrm{NO}_{2}+\mathrm{OH} \rightarrow \mathrm{He}+\mathrm{HNO}_{3}$ & 102 \\
118 & $\mathrm{He}+\mathrm{NO}_{2}+\mathrm{NO}_{3} \rightarrow \mathrm{He}+\mathrm{N}_{2} \mathrm{O}_{5}$ & 103 \\
\hline \hline
\end{tabular}

${ }^{a}$ The reaction rate coefficient has a unit of $\mathrm{s}^{-1}$ for the single-body reactions, $\mathrm{cm}^{3} \mathrm{~s}^{-1}$ for the two-body reactions and $\mathrm{cm}^{6} \mathrm{~s}^{-1}$ for three-body reactions.

${ }^{\mathrm{b}}$ The rate coefficient is obtained from EEDF (electron energy distribution function) using cross sections from indicated reference.

${ }^{\mathrm{c}}$ Cross section for R12 is not well established. In Ref. 78 the cross section for $\sim 15 \mathrm{eV}$ electrons is estimated to be $4 \times 10^{-17} \mathrm{~cm}^{2}$. To get a reaction rate as a function of $\mathrm{T}_{\mathrm{e}}$, a constant cross section of $4 \times 10^{-18} \mathrm{~cm}^{2}$ is assumed here.

\section{REFERENCES}

${ }^{1}$ M. Laroussi, C. Tendero, X. Lu, S. Alla, and W. L. Hynes, Plasma Process Polym. 3, 470 (2006)

${ }^{2}$ R. E. J. Sladek and E. Stoffels, J. Phys. D 38, 1716 (2005).

${ }^{3}$ H. W. Herrmann, I. Henins, J. Park, and G. S. Selwyn, Phys. Plasmas 6, 2284-2289 (1999)

${ }^{4}$ S. Galvin, O. Cahill, N. O’Connor, A. A. Cafolla, S. Daniels, and H. Humphreys, Lett. Appl. Microbiol. 57, 83-90 (2013).

${ }^{5}$ J. He, J. T. Hu, D. W. Liu, and Y. T. Zhang, Plasma Sources Sci. Technol. 22, 035008 (2013)

${ }^{6}$ H. Zhang, J. Ma, J. Shen, Y. Lan, L. L. Ding, S. L. Qian, C. Cheng, W. D. Xia, and P. K. Chu, IEEE Trans. Plasma Sci. 46, 2742 (2018).

${ }^{7}$ J. Shen, H. Zhang, Z. M. Xu, Z. L. Zhang, C. Cheng, G. H. Ni, Y. Lan, Y. D. Meng, W. D. Xia, and P. K. Chu, Chem. Eng. J. 362, 402 (2019).

${ }^{8}$ T. Shao, F. Liu, B. Hai, Y. Ma, R. Wang, and C. Ren, IEEE Trans. Dielectr. Electr. Insul, 24, 1557 (2017).

${ }^{9}$ P. Bao, X. P. Lu, M. B. He, and D. W. Liu, IEEE Trans. Plasma Sci. 44, 2673 (2016).

${ }^{10}$ K. H. Cheeseman and T. F. Slater, Br. Med. Bull. 49, 481 (1993).

${ }^{11}$ B. Haertel, V. T. Woedtke, K. D. Weltmann, and U. Lindequist, Biomol. Ther. 22, 477 (2014).

${ }^{12}$ A. B. Shekter, V. A. Serezhenkov, T. G. Rudenko, A. V. Pekshev, and A. F. Vanin, Nitric Oxide 12, 210 (2005).

${ }^{13}$ M. R. Schaffer, U. Tantry, and A. Barbul, J. Surg. Res. 71, 25 (1997).

${ }^{14}$ N. Knake, S. Reuter, K. Niemi, V. S. Gathen, and J. Winter, J. Phys. D 41, 194006 (2008).

${ }^{15}$ T. Martens, A. Bogaerts, W. J. M. Brok, and J. V. Dijk, Appl. Phys. Lett. 92, 041504 (2008).

${ }^{16}$ A. Bourdon, T. Darny, F. Pechereau, J. M. Pouvesle, P. Viegas, S. Iséni, and E. Robert, Plasma Sources Sci. Technol. 25, 035002 (2016).

${ }^{17}$ X. Yuan and L. L. Raja, Appl. Phys. Lett. 81, 814 (2002).

${ }^{18}$ Y. H. Wang and D. Z. Wang, Phys. Plasmas 12, 023503 (2005).

${ }^{19} \mathrm{G}$. Willems, J. Golda, D. Ellerweg, J. Benedikt, A. Keudell, N. Knake, and V. Gathen, New J. Phys. 12, 013021 (2010).

${ }^{20}$ K. McKay, D. Donaghy, F. He, and J. W. Bradley, Plasma Sources Sci. Technol. 27, 015002 (2017).

${ }^{21}$ X. Lu, M. Laroussi, and V. Puech, Plasma Sources Sci. Technol 21, 034005 (2012).

${ }^{22}$ A. A. Panarin, V. S. Skakun, E. A. Sosnin, and V. F. Tarasenko, Opt. Spectrosc. 122, 168 (2017).

${ }^{23}$ W. C. Zhu, Q. Li, X. M. Zhu, and Y. K. Pu, J. Phys. D 42, 202002 (2009).
${ }^{24}$ H. Xu, C. Chen, D. X. Liu, W. T. Wang, W. J. Xia, Z. J. Liu, L. Guo, and M. G. Kong, Plasma Sci. Technol. 21, 115502 (2019).

${ }^{25}$ Z. Y. Chen, Q. J. Cui, C. Chen, D. H. Xu, D. X. Liu, H. L. Chen, and M. G. Kong, Phys. Plasmas 25, 023508 (2018).

${ }^{26}$ N. Y. Babaeva and G. V. Naidis, Trends Biotechnol. 36, 603 (2018).

${ }^{27}$ J. L. Hobman, P. A. Lund, C. J. Kershaw, G. A. Hidalgo-Arroyo, C. W. Penn, X. T. Deng, J. L. Walsh, and M. G. Kong, Appl. Phys. Lett. 90, 073902 (2007).

${ }^{28}$ X. P. Lu, T. Ye, Y. G. Cao, and Z. Y. Sun, J. Appl. Phys. 104, 053309 (2008).

${ }^{29}$ B. W. Sun, D. X. Liu, F. Iza, S. Wang, A. J. Yang, Z. J. Liu, M. Z. Rong, and X. H. Wang, Plasma Sources Sci. Technol. 28, 035006 (2019)

${ }^{30}$ S. Schröter, A. Wijaikhum, A. R. Gibson, W. Andrew, H. L. Davies, N. Minesi, J. Dedrick, E. Wagenaars, N. Oliveira, L. Nahon, M. J. Kushner, J. P. Booth, K. Niemi, T. Gans, and D. O'Connell, Phys. Chem. Chem. Phys. 20, 24263 (2018)

${ }^{31}$ T. Murakami, K. Niemi, T. Gans, D. O'Connell, and W. G. Graham, Plasma Sources Sci. Technol. 22, 015003 (2012).

${ }^{32}$ C. Chen, D. X. Liu, Z. C. Liu, A. J. Yang, H. L. Chen, G. Shama, and M. G. Kong, Plasma Chem. Plasma Process. 34, 403 (2014).

${ }^{33}$ C. Lazarous, A. S. Chiper, C. Anastassiou, I. Topala, I. Mihaila, V. Pohoata, and G. E. Georghious, J. Phys. D 52, 195203 (2019).

${ }^{34}$ A. J. Yang, D. X. Liu, M. Z. Rong, X. H. Wang, and M. G. Kong, Phys. Plasmas 21, 083501 (2014).

${ }^{35}$ A. J. Yang, M. Z. Rong, X. H. Wang, D. X. Liu, and M. G. Kong, J. Phys. D 46, 415201 (2013).

${ }^{36}$ A. J. Yang, X. H. Wang, M. Z. Rong, D. X. Liu, F. Iza, and M. Z. Kong, Phys. Plasmas 18, 113503 (2011).

${ }^{37}$ D. X. Liu, A. J. Yang, X. H. Wang, M. Z. Rong, F. Iza, and M. G. Kong, . Phys. D 45, 305205 (2012).

${ }^{38}$ D. X. Liu, X. H. Wang, M. Z. Rong, F. Iza, M. G. Kong, and P. Bruggeman, Plasma Processes Polym. 7, 846 (2010).

${ }^{39}$ K. McKay, D. X. Liu, M. Z. Rong, F. Iza, and M. G. Kong, J. Phys. Appl. Phys, 45, 172001 (2012).

${ }^{40}$ K. McKay, D. X. Liu, F. Iza, M. Z. Rong, and M. G. Kong, IEEE Trans. Plasma Sci. 39, 2138 (2011).

${ }^{41}$ C. O. Laux, T. G. Spence, C. H. Kruger, and R. N. Zare, Plasma Sources Sci. Technol. 12, 125 (2003).

${ }^{42}$ F. Iza, G. J. Kim, S. M. Lee, J. K. Lee, J. L. Walsh, Y. T. Zhang, and M. G. Kong, Plasma Processes Polym. 5, 322 (2008).

${ }^{43}$ F. Iza, J. L. Walsh, and M. G. Kong, IEEE Trans. Plasma Sci. 37, 1289 (2009).

${ }^{44}$ B. W. Sun, D. X. Liu, A. J. Yang, M. Z. Rong, and X. H. Wang, Phys. Plasmas 26, 123508 (2019). 
${ }^{45}$ Y. H. Zhang, W. J. Ning, D. Dai, and Q. Wang, Plasma Sources Sci. Technol. 28, 075003 (2019).

${ }^{46}$ P. S. Kothnur and L. L. Raja, J. Appl. Phys. 97, 043305 (2005).

${ }^{47}$ P. S. Kothnur, X. Yuan, and L. L. Raja, Appl. Phys. Lett. 82, 529 (2003).

${ }^{48}$ Y. Sakiyama and D. B. Graves, J. Appl. Phys. 101, 073306 (2007).

${ }^{49}$ B. Twomey, A. Nindrayog, K. Niemi, W. G. Graham, and D. P. Dowling, Plasma Chem. Plasma Process. 31, 139 (2011).

${ }^{50}$ Q. Xiong, A. Y. Nikiforov, M. Á. González, C. Leys, and X. P. Lu, Plasma Sources Sci. Technol. 22, 015011 (2012).

${ }^{51}$ D. Z. Yang, W. C. Wang, K. L. Wang, F. Liu, and D. Z. Wang, Spectrochim. Acta Part A 76, 224 (2010).

${ }^{52}$ N. Jiang, C. Qiu, L. Guo, K. Shang, N. Lu, J. Li, and Y. Wu, Plasma Chem. Plasma Process. 39, 227 (2019).

${ }^{53}$ N. Bundaleska, D. Tsyganov, R. Saavedra, E. Tatarova, F. M. Dias, and C. M. Ferreira, Int. J. Hydrogen Energy 38, 9145-9157 (2013).

${ }^{54}$ N. Knake, K. Niemi, S. Reuter, V. S. Gathen, and J. Winter, Appl. Phys. Lett. 93, 131503 (2008).

${ }^{55}$ X. T. Deng, J. J. Shi, and M. G. Kong, J. Appl. Phys. 101, 074701 (2007).

${ }^{56}$ G. Y. Park, Y. J. Hong, H. W. Lee, J. Y. Sim, and J. K. Lee, Plasma Processes Polym. 7, 281 (2010).

${ }^{57}$ B. A. Schmidt, R. Bansemer, S. Reuter, and K. D. Weltmann, Plasma Processes Polym. 13, 1120 (2016).

${ }^{58}$ L. Chandana, C. J. Sangeetha, T. Shashidhar, and C. Subrahmanyam, Sci. Total Environ. 640, 493 (2018).

${ }^{59}$ K. McKay, F. Iza, and M. G. Kong, Eur. Phys. J. D 60, 497 (2010).

${ }^{60}$ Z. L. Zhang, Q. Y. Nie, Z. B. Wang, X. T. Gao, F. R. Kong, Y. F. Sun, and B. H. Jiang, Phys. Plasmas 23, 073501 (2016).

${ }^{61}$ J. J. Shi and M. G. Kong, Phys. Rev. Lett. 96, 105009 (2006).

${ }^{62}$ K. McKay, D. X. Liu, M. Z. Rong, F. Iza, and M. G. Kong, Appl. Phys. Lett. 99, 091501 (2011).

${ }^{63}$ W. J. Ning, D. Dai, and L. C. Li, Plasma Sources Sci. Technol. 27, 08LT01 (2018).

${ }^{64}$ D. D. Monahan and M. M. Turner, Plasma Sources Sci. Technol. 17, 045003 (2008).

${ }^{65}$ D. X. Liu, F. Iza, X. H. Wang, Z. Z. Ma, M. Z. Rong, and M. G. Kong, Plasma Sources Sci. Technol. 22, 055016 (2013).

${ }^{66}$ D. W. Liu, F. Iza, and M. G. Kong, Appl. Phys. Lett. 95, 031501 (2009).

${ }^{67}$ Y. Sakiyama, D. B. Graves, H. W. Chang, T. Shimizu, and G. E. Morfill, J. Phys. D 45, 425201 (2012).

${ }^{68}$ H. Cheng, X. Liu, X. Lu, and D. Liu, Phys. Plasmas 23, 073517 (2016).

${ }^{69}$ D. X. Liu, P. Bruggeman, F. Iza, M. Z. Rong, and M. G. Kong, Plasma Sources Sci. Technol. 19, 025018 (2010).

${ }^{70}$ R. Henry, P. Burke, and A. L. Sinfailam, Phys. Rev. 178, 218-225 (1969).

${ }^{71}$ C. P. Malone, P. V. Johnson, X. Liu, B. Ajdari, I. Kanik, and M. A. Khakoo, Phys. Rev. A 85, 062704 (2012).

${ }^{72}$ G. J. M. Hagelaar and L. C. Pitchford, Plasma Sources Sci. Technol. 14, 722 (2005).

${ }^{73}$ R. R. Laher and F. R. Gilmore, J. Phys. Chem. Ref. Data 19, 277-305 (1990).

${ }^{74}$ Y. Itikawa, A. Ichimura, K. Onda, K. Sakimoto, K. Takayanagi, Y. Hatano, M. Hayashi, H. Nishimura, and S. Tsurubuchi, J. Phys. Chem. Ref. Data 18, 23 (1989).

${ }^{75}$ B. Eliasson and U. Kogelschatz, "Basic data for modelling of electrical discharges in gases: Oxygen," Technical Report No. KLR 86-11 C (ABB Asea Brown Bover, 1986).

${ }^{76}$ M. Yousfi and M. D. Benabdessadok, J. Appl. Phys. 80, 6619 (1996).

${ }^{77}$ Y. Itikawa and N. Mason, J. Phys. Chem. Ref. Data 34(1), 1 (2005).

${ }^{78}$ K. N. Joshipuru, M. Vinodkumar, and U. M. Patel, J. Phys. B 34, 509 (2001).
${ }^{79}$ I. A. Soloshenko, V. V. Tsiolko, S. S. Pogulay, A. G. Terent'yeva, V. Y. Bazhenov, A. I. Shchedrin, A. V. Ryabtsev, and A. I. Kuzmichev, Plasma Sources Sci. Technol. 16, 56 (2007).

${ }^{80}$ D. Rapp and D. D. Briglia, J. Chem. Phys. 43, 1480-1489 (1965).

${ }^{81}$ J. W. McConkey, C. P. Malone, P. V. Johnson, C. Winstead, V. Mckoy, and I. Kanik, Phys. Rep. 466, 1-103 (2008).

${ }^{82}$ H. Matzing, Adv. Chem. Phys. 80, 315-402 (2007).

${ }^{83}$ M. Capitelli, C. M. Ferreira, B. F. Gordiets, and A. I. Osipov, Plasma Kinetics in Atmospheric Gases (Springer, Berlin, 2000).

${ }^{84}$ I. A. Kossyi, A. Y. Kostinsky, A. A. Matveyen, and V. P. Silakov, Plasma Sources Sci. Technol. 1, 207 (1992).

${ }^{85}$ L. W. Sieck, J. T. Herron, and D. S. Green, Plasma Chem. Plasma Process. 20, 235 (2000).

${ }^{86}$ V. G. Anicich, J. Phys. Chem. Ref. Data 22, 1469 (1993).

${ }^{87}$ R. Dorai and M. J. Kushner, J. Phys. D 36, 666 (2003).

${ }^{88}$ R. E. Olson, J. R. Peterson, and J. T. Moseley, J. Chem. Phys. 53, 3391 (1970).

${ }^{89} \mathrm{M}$. H. Bortner and T. Baurer, "Defense nuclear agency reaction rate handbook," Final Report No. AD-763699, DNA-1948-H (General Electric Co., Philadelphia, 1972).

${ }^{90}$ T. D. Mark and H. J. Oskam, Phys. Rev. A 4, 1445 (1971).

${ }^{91}$ A. Cenian, A. Chernukho, and V. Borodin, Contrib. Plasma Phys. 35, 273 (1995).

${ }^{92}$ R. J. Vidmar and K. R. Stalder, "Computations of the power to sustain plasma in air with relevance to aerospace technology," Air Force Office of Scientific Research, AFOSR Final Performance Report No. AFRISRARRE040123 and F49620-01-0414 (2004).

${ }^{93}$ R. L. Champion, L. D. Doverspike, and S. K. Lam, Phys. Rev. A 13, 617-621 (1976).

${ }^{94}$ E. W. McDaniel, M. R. Flannery, E. W. Thomas, H. W. Ellis, K. J. McCann, S. T. Manson, J. W. Gallagher, J. R. Rumble, E. C. Beaty, and T. G. Roberts, Technical Report No. H-78-1 (US Army Missile Research and Development Command, 1978).

${ }^{95}$ R. P. Cardoso, T. Belmonte, G. Henrion, and N. Sadeghi, J. Phys. D 39, 4178 (2006).

${ }^{96}$ D. S. Stafford and M. J. Kushner, J. Appl. Phys. 96, 2451 (2004).

${ }^{97}$ T. Shibata, T. Fukuyama, and K. Kuchitsu, J. Mass Spectrom. Soc. Jpn. 21, 217 (1973).

${ }^{98}$ Y. B. Golubovskii, V. A. Maiorov, J. Behnke, and J. F. Behnke, J. Phys. D 36, 39 (2003).

${ }^{99}$ K. Niemi, J. Waskoenig, N. Sadeghi, T. Gans, and D. O’Connell, Plasma Sources Sci. Technol. 20, 055005 (2011).

${ }^{100}$ B. M. Smirnov, Ions and Excited Atoms in Plasma (Atomizdat, Moscow) (in Russian) (1974).

${ }^{101}$ F. Tochikubo and H. Arai, Jpn. J. Appl. Phys., Part 1 41, 844 (2002).

${ }^{102}$ J. T. Herron and D. S. Green, Plasma Chem. Plasma Process. 21, 459 (2001).

${ }^{103}$ R. Atkinson, D. L. Baulch, R. A. Cox, R. F. Hampson, J. A. Kerr, M. J. Rossi, and J. Troe, J. Phys. Chem. Ref. Data 26, 1329 (1997).

${ }^{104}$ M. J. Kushner, J. Appl. Phys. 74, 6538 (1993).

${ }^{105}$ S. E. Babayan, G. Ding, and R. F. Hicks, Plasma Chem. Plasma Process. 21, 505 (2001).

${ }^{106}$ W. R. Binns and J. L. Ahl, J. Chem. Phys. 68, 538 (1978).

${ }^{107}$ T. Koike and K. Morinaga, Bull. Chem. Soc. Jpn. 55, 52 (1982).

${ }^{108}$ R. A. Copeland and D. R. Crosley, J. Chem. Phys. 84, 3099 (1986).

${ }^{109}$ A. C. Gentile and M. J. Kushner, J. Appl. Phys. 78, 2074 (1998).

${ }^{110}$ See http://me.berkeley.edu/gri-mech/ for "GRI-MECH 3 Reaction Rate Database."

${ }^{11}$ M. Castillo, I. M'endez, A. M. Islyaikin, V. J. Herrero, and I. Tanarro, J. Phys. Chem. A 109, 6255 (2005). 